\title{
III. Biochemistry of S-layers ${ }^{1}$
}

\author{
Paul Messner ${ }^{2, \mathrm{a}}$, Günter Allmaier ${ }^{2,3, \mathrm{e}}$, Christina Schäffer ${ }^{3, \mathrm{a}}$, Thomas Wugeditsch ${ }^{\mathrm{a}}$, \\ Sylvie Lortal ${ }^{3, b}$, Helmut König ${ }^{3, c}$, Ruth Niemetz ${ }^{d}$, Maria Dorner ${ }^{\text {e }}$ \\ a Zentrum für Ultrastrukturforschung und Ludwig Boltzmann-Institut für Molekulare Nanotechnologie, Universität für Bodenkultur, \\ A-1180 Wien, Austria \\ b INRA-Technologie Laitière, 65 rue de St Brieuc, F-35042 Rennes Cedex, France \\ c Institut für Mikrobiologie und Weinforschung, Johannes Gutenberg-Universität, D-55099 Mainz, Germany \\ d Angewandte Mikrobiologie, Universität Ulm, D-89069 Ulm, Germany \\ e Institut für Analytische Chemie, Universität Wien, A-1090 Wien, Austria
}

Received 10 March 1997; accepted 24 March 1997

\begin{abstract}
During evolution prokaryotes have developed different envelope structures exterior to the cell wall proper. Among these surface components are regularly arranged S-layers and capsules. The structural characterization and the detailed chemical analysis of these surface molecules is a prerequisite to understand their biosynthesis and functional role(s) at the molecular level. Of particular interest are the glycosylated S-layer proteins which belong to the first prokaryotic glycoproteins ever described. Their characterization was performed on strains belonging to the thermophilic Bacillaceae and included structural studies and experiments to learn about the pathways for the glycan biosynthesis of S-layer glycoproteins. As an example for non-glycosylated S-layer proteins those of Lactobacillus helveticus strains are described in detail. Recently, a novel type of bacterial glycoconjugate was observed in the cell envelope of the extremely halophilic archaeon Natronococcus occultus which consists of a glycosylated polyglutamyl polymer. Beside the conventional biochemical techniques for the analysis new sophisticated instrumental methods such as X-ray photoelectron spectroscopy and matrix-assisted laser desorption ionization or electrospray ionization mass spectrometry have been introduced for the analysis of the protein and glycan portions of these cell surface macromolecules.
\end{abstract}

Keywords: S-layer; Bacillaceae; Glycoprotein; Capsule; Natronococcus; Lactobacillius; Polyglutamate; Glycon structure; Mass spectrometry

\footnotetext{
1 This review is part of a series of reviews dealing with different aspects of bacterial S-layers; all these reviews appeared in Volume 20/1-2 (June 1997) of FEMS Microbiology Reviews, thematic issue devoted to bacterial S-layers.

${ }^{2}$ Guest Editors

${ }^{3}$ Corresponding authors.
}

0168-6445/97/\$32.00 (C) 1997 Federation of European Microbiological Societies. Published by Elsevier Science B.V.

PII S $0168-6445(97) 00041-7$ 


\section{Contents}

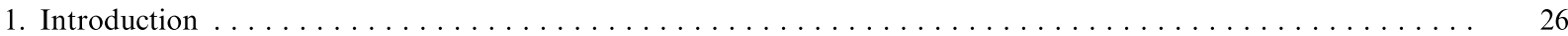

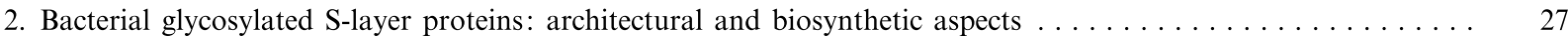

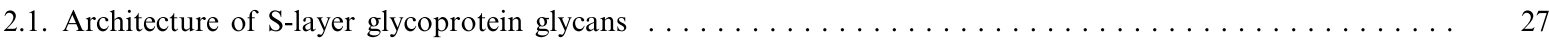

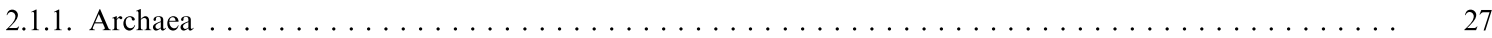

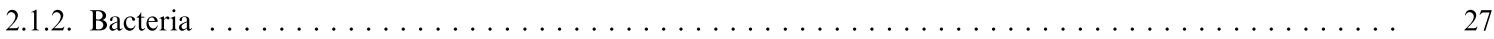

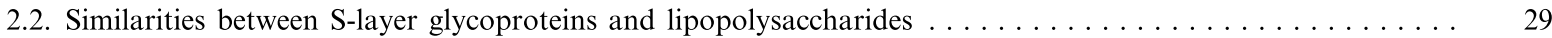

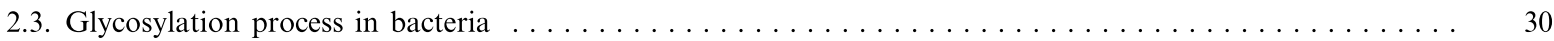

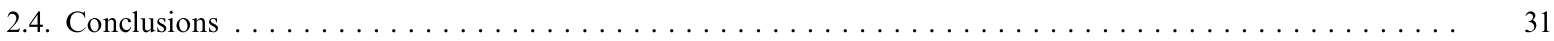

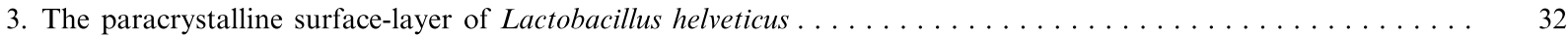

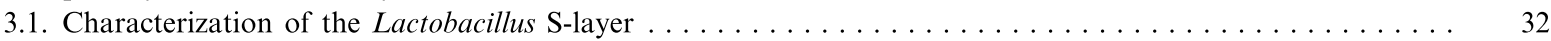

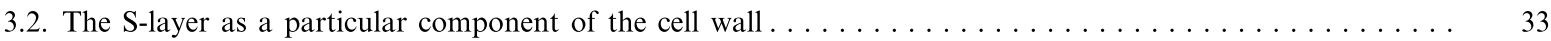

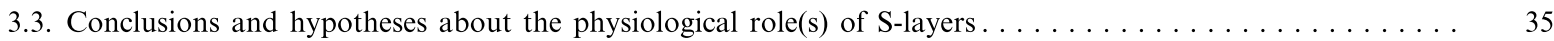

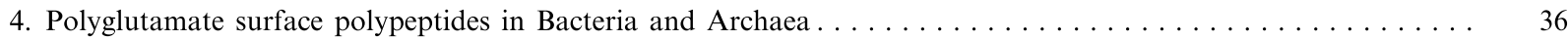

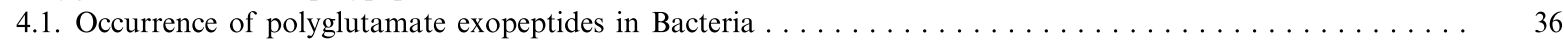

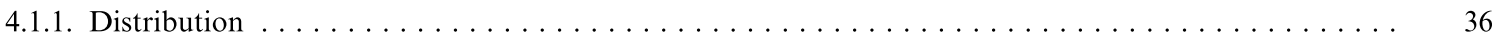

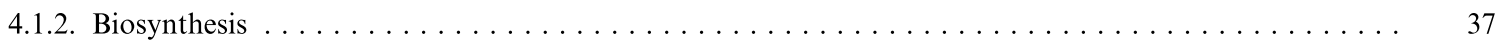

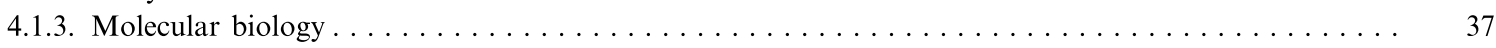

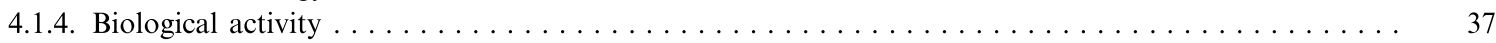

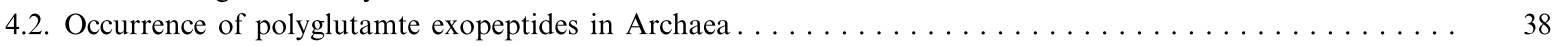

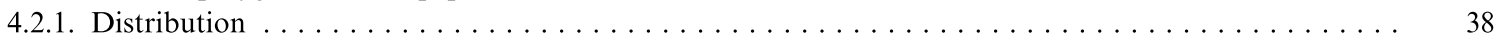

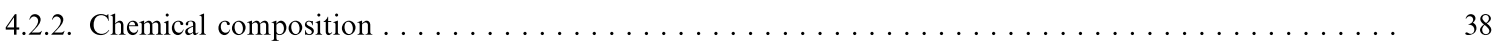

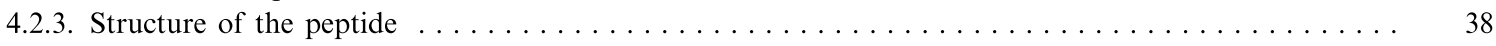

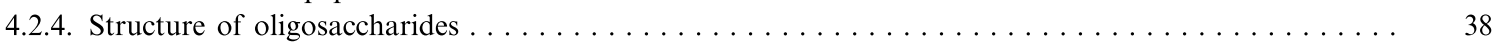

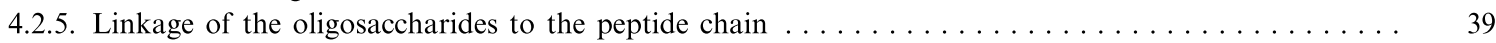

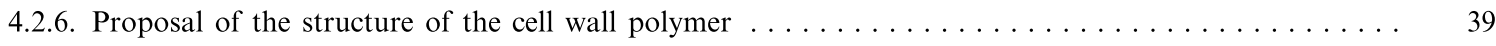

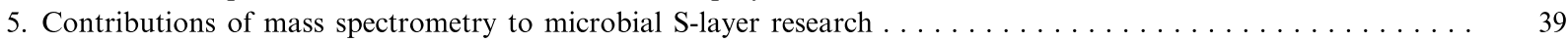

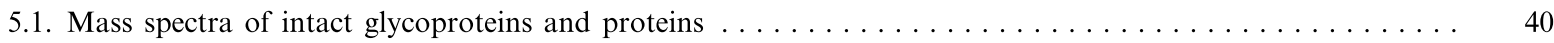

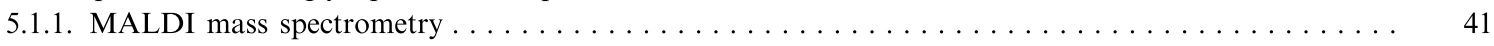

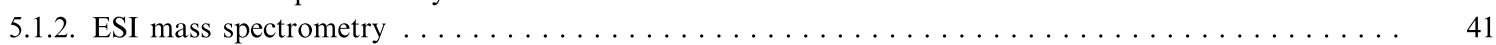

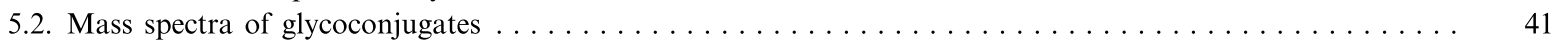

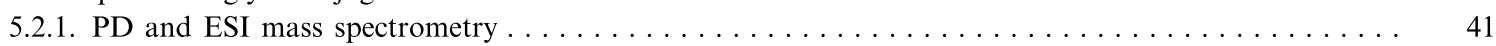

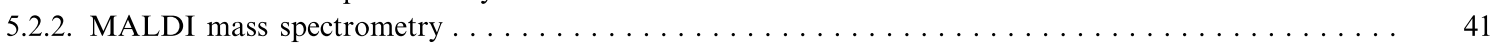

5.2.3. Fragmentation of glycoconjugates inside the mass spectrometer $\ldots \ldots \ldots \ldots \ldots \ldots \ldots \ldots \ldots$. 41

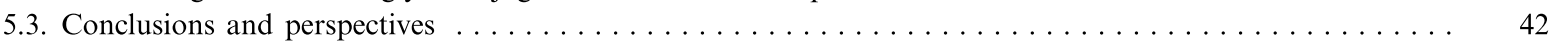

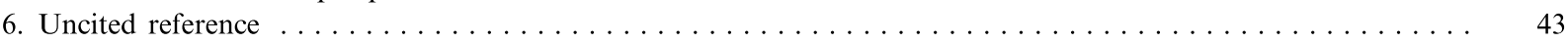

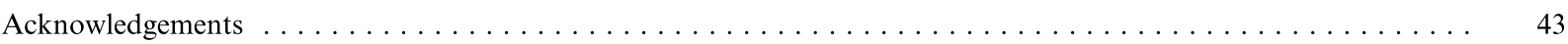

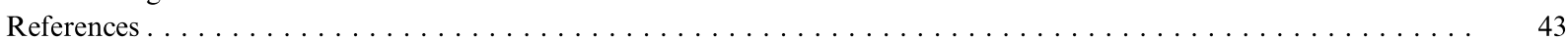

\section{Introduction}

During evolution prokaryotes have developed different envelope structures exterior to the cell wall proper. Among these surface components are regularly arranged S-layers (composed of protein or glycoprotein subunits) and capsules. A detailed chemical analysis of these surface molecules is a prerequisite to understand their biosynthesis and function. Advanced analytical methods are required for structure elucidation. The biosynthesis of the S-layer constituents raises many intriguing questions, e.g. transport accross the cytopasmic and outer membranes, glycosylation, further processing and biological activity. This review deals with the different aspects of the biochemistry of S-layers. 
2. Bacterial glycosylated S-layer proteins: architectural and biosynthetic aspects

\author{
Christina Schaffer ${ }^{3}$, Thomas Wugeditsch, \\ Paul Messner
}

S-layer glycoproteins have been established as constituents of archaeal [1-3] as well as of bacterial cell envelopes [3-5]. They form crystalline arrays composed of homogeneous glycoprotein species exhibiting a considerable variety of glycan structures, none of which is known to occur in eukaryotes. In comparison to eukaryotic glycoproteins the number of prokaryotic glycoproteins known so far is rather small (approximately 20 different S-layer glycans structures). Despite this limitation in number, the glycan structures of all S-layer glycoproteins investigated, together with the available information on the composition of analyzed carbohydrate-protein linkage regions, led to some generalizations concerning the architecture of S-layer glycoprotein glycans. From biosynthetic studies on S-layer glycoproteins insight into the pathways of the prokaryotic glycosylation process could be obtained.

\subsection{Architecture of S-layer glycoprotein glycans}

\subsubsection{Archaea}

With one exception, all archaeal S-layer glycans characterized so far, consist of short linear chains of only a few (approximately up to 10) sugar residues [2,6]. Many of the glycan chains are linked to the S-layer polypeptide by $N$-glycosidic linkages, such as Glc $\rightarrow$ Asn (Halobacterium halobium, Haloferax volcanii) [7], GalNAc $\rightarrow$ Asn (H. halobium, Methanothermus fervidus) [2,6], and Rha $\rightarrow$ Asn (Methanothrix soehngenii) [8]. On the other hand, $O$-glycosidic linkages via threonine, such as $\mathrm{Gal} \rightarrow \mathrm{Thr}$ (H. halobium, H. volcanii) [1,9] are also common. Besides low-molecular-mass sulfated oligosaccharides and neutral disaccharides, a heavily sulfated heteropolysaccharide, which represents the only high-molecular-mass archaeal S-layer glycan known so far, is bound to the S-layer protein of H. halobium $[1,2]$.

\subsubsection{Bacteria}

Among bacteria glycosylated S-layer proteins have been demonstrated only for organisms belonging to the family of Bacillaceae (species Bacillus, Paenibacillus, Thermoanaerobacterium, Thermoanaerobacter, Clostridium, Desulfotomaculum) [3] and for Lactobacillus [10]. Bacterial S-layer glycoprotein glycans usually consist of long homo- or heteropolysaccharide chains composed of identical linear or branched repeating units $[3,5]$ with an overall chain length ranging up to 150 monosaccharide residues [3]. Presently, only in the S-layer glycan of Lactobacillus buchneri [10] and Thermoanaerobacter thermohydrosulfuricus S102-70 [11] short oligosaccharides have been described. Both, conventional and completely new protein-carbohydrate linkage regions have been identified. $O$-glycosidic linkages to the apoprotein are more frequently observed than $N$-glycosidic ones; in fact, the only $N$-glycan, Rha $\rightarrow$ Asn, has been described in Bacillus stearothermophilus NRS 2004/3a [12]. Beside the $O$-glycosidic linkage via serine, e.g., Glc $\rightarrow$ Ser in L. buchneri [10], completely new types of linkages have been found, such as $\mathrm{Tyr} \rightarrow \mathrm{Glc}$ (Th. thermohydrosulfuricus $\mathrm{S} 102-70$ ) [11] and $\mathrm{Tyr} \rightarrow \mathrm{Gal}$ (Th. thermohydrosulfuricus L111-69, Paenibacillus alvei CCM 2051) [13,14]. Although not characterized in detail, Tyr has been found as the only amino acid constituent in several glycopeptide preparations derived from different Th. thermohydrosulfuricus strains [15]. Further, in Thermoanaerobacter kivui [16] (formerly Acetogenium kivui), four modified tyrosine residues which most probably represent $O$-glycosylation sites have been identified [17]. This might implicate that $O$-glycosylation via tyrosine is characteristic for the genus Thermoanaerobacter.

From those data it is obvious that the glycans of bacterial S-layer glycoproteins differ considerably from eukaryotic ones. Even individual strains of a species can exhibit a remarkable degree of heterogeneity regarding the structural organization and chemical composition of the crystalline array.

Structure elucidation of S-layer glycans was achieved by a combination of chemical methods, including periodate oxidation, Smith-type hydrolysis, methylation analysis, and 1D and $2 \mathrm{D}{ }^{1} \mathrm{H}$ and ${ }^{13} \mathrm{C}$ NMR spectroscopy. Analyses were performed on glycopeptides which were obtained after exhaustive proteolytic digestion of S-layer subunits with pronase $\mathrm{E}$ and purified by gel-permeation chromatogra- 
phy, CIEC, chromatofocusing and reversed phaseHPLC [3].

In the S-layer glycoprotein of Th. thermohydrosulfuricus L111-69 at least 4 different $O$-glycosylation sites via tyrosine are present [13], carrying identical glycan chains composed of linear heteropolymer repeats of the structure -3 $\alpha$ LRhap $1-4 \alpha$ DMan $p 1-$ [14]. At the non-reducing end of the carbohydrate moiety 3-O-methyl-rhamnose was found. This type of chemical modification of sugars is discussed in conjunction with the termination of the glycosylation reaction in archaeal glycan chains ( $H$. halobium, $H$. volcanii) [1]. Whether the present 3-O-methylrhamnose actually acts as a termination signal in this microorganism remains to be established.

The microheterogeneity concerning the chain length of the glycan could be well documented by the means of matrix-assisted laser desorption ionization mass spectrometry [14]. In strain L111-69 polymerization degrees of 23 to 32 disaccharide repeats occur. The most abundant ion was detected at $\mathrm{m} / \mathrm{z}$ 9,478.3 which corresponds to 27 repeats.

Some microorganisms are also capable of presenting differently composed carbohydrate chains on the cell surface. In Thermoanaerobacterium thermosaccharolyticum E207-71, for instance, after chromatofocusing of the prepurified proteolytic digest of the S-layer glycoprotein, three major glycopeptide fractions and one minor fraction were obtained [18]. They correspond to at least three different glycosylation sites for the major glycan, which contains a rather complex hexasaccharide consisting of an $-4 \alpha$ DMan $p 1-4 \beta$ DGal $p 1-4 \beta$ DGlc $p 1$ - backbone with

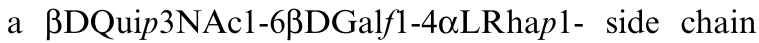
attached to oxygen 3 of the mannose residue [18]. Tyrosine most probably represents the linkage amino acid. The minor glycopeptide fraction consists of pentasaccharide repeats built of -3ßDMan $p$ NAc1$4 \beta$ DGlc $p$ NAc1- with $\alpha$ DRibf attached to every second ManNAc residue [19]. Interestingly, the S-layer glycoprotein of Th. thermosaccharolyticum D120-70 also bears two different glycans [20]. The amino sugar-rich polymer has a composition rather similar to that of E207-71 but in D120-70 galactose is present instead of ribofuranose. Whether this finding reflects a common assembly principle among glycosylated S-layers of Th. thermosaccharolyticum strains remains to be established.
During the past few years the glycan structures of S-layer glycoproteins from several strains of the genera Bacillus, Thermoanaerobacterium, and Thermoanaerobacter were elucidated [3,5]. Table 1 reveals the inherent variability in structure and composition of the carbohydrate chains of selected organisms [21].

The S-layer glycoprotein of strain Bacillus thermoaerophilus DSM 10155, which belongs to a newly described Bacillus species [22], revealed two unusual properties. First, due to the observed water solubility of the S-layer glycoprotein the conventional isolation procedure [14] had to be replaced by a combination of water extraction followed by a modified interfacial salting out. Second, D-glycero-D-manno-heptose was found as constituent of the disaccharide repeat

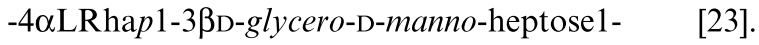
Heptoses are typical constituents of the core region of the $O$-antigens of LPS of Gram-negative bacteria, where they occur either in the L-glycero-D-manno- or D-glycero-D-manno-configuration (e.g., Vibrio cholerae, Vibrio parahaemolyticus) [24,25]. Several other unusual sugars which until now have been known as typical constituents of LPS have also been found in S-layer glycans (indicated by boxes in Table 1): 3-acetamido-3,6-dideoxy-D-glucose (quinovosamine), for example found in the LPS of Proteus penneri, Vibrio mimicus [26,27], is part of the side chain of the hexasaccharide repeat of $T h$. thermosaccharolyticum E207-71 [18], and D-rhamnose and 3-acetamido-3-deoxy- $\alpha$-D-fucose, frequently observed in LPS [28], are constituents of the complex hexasaccharide repeat of Bacillus thermoaerophilus L420-91 [29].

Comparison of the S-layer glycoprotein glycans of P. alvei CCM 2051 and Th. thermohydrosulfuricus L111-69 showed that the $O$-antigen like regions are linked to the respective S-layer polypeptides via an almost identical tetrasaccharide core composed of $-3 \alpha$ LRhap $1-3 \alpha$ LRhap $1-3 \alpha$ LRhap $1-3 \beta D G a l p 1-$ (indicated by shaded boxes in Table 1). In P. alvei, however, the non-reducing rhamnose residue is additionally substituted at oxygen 4 with a phosphorylated short side chain. The reducing $\beta \mathrm{DGal} p$ residues of both cores are $O$-glycosidically linked to tyrosine residues [13]. This observation indicates that certain structural motifs remain unchanged even amongst phylogenetically rather distant organisms. 
Table 1

Glycan structures of select eubacterial S-layer glycoproteins ${ }^{\mathrm{a}}$

\begin{tabular}{|c|c|}
\hline Strain & Ref. \\
\hline 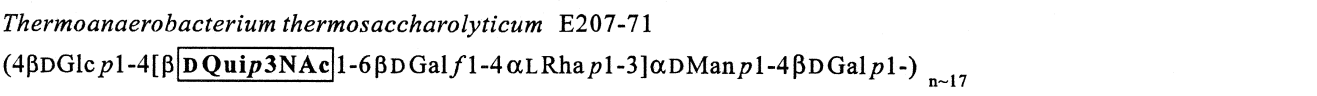 & [18] \\
\hline $\begin{array}{l}\text { Bacillus thermoaerophilus L420-91 } \\
\text { (3[ }[\text { DFucp3NAc } 1-2] \alpha \text { DRhap } 1-3[\alpha \text { DFuc } p 3 \text { NAc1-2] } \alpha \text { DRha } p 1-2 \alpha \text { DRha } p 1-2 \alpha \text { DRha } p 1-)_{\mathrm{n}}\end{array}$ & [29] \\
\hline $\begin{array}{l}\text { Bacillus thermoaerophilus } \\
(4 \alpha \text { L Rha } p 1-3 \beta \text { D-glycero-D-manno-Hep } p 1-)_{\mathrm{n}}\end{array}$ & [23] \\
\hline $\begin{array}{l}\text { Thermoanaerobacter thermohydrosulfuricus L111-69 } \\
3 O \mathrm{Me} \alpha \mathrm{LRha} p 1-4 \alpha \mathrm{DMan} p 1-[3 \alpha \mathrm{L} \text { Rha } p 1-4 \alpha \mathrm{DMan} p 1]_{\mathrm{n} \sim 27}-3 \alpha \text { L Rha } p 1-3 \alpha \text { L Rha } p 1-3 \alpha \text { I Rha } p 1-3 \beta \text { D Gal } p 1-O-\mathrm{Tyr}\end{array}$ & [14] \\
\hline 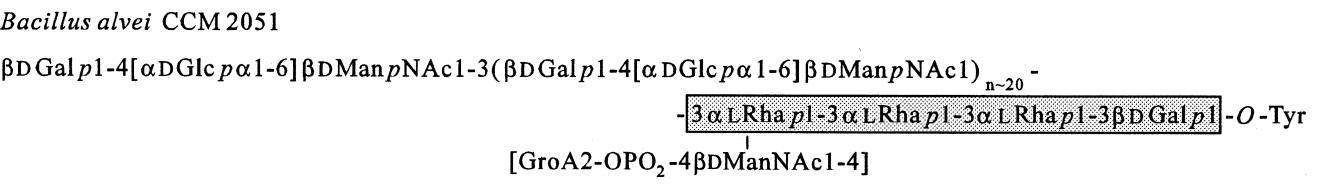 & [13] \\
\hline
\end{tabular}

${ }^{a}$ Sugars which are known as typical constituents of LPS are marked by boxes.

Shaded boxes indicate core structures in S-layer glycoproteins between repeating units and the S-layer polypeptides.

\subsection{Similarities between S-layer glycoproteins and lipopolysaccharides}

The strain-specific composition of identical repeats occurring in different degrees of polymerization [3], which is realized in S-layer glycoprotein glycans, reflects the non-conservative character of bacterial cell surface carbohydrates [30,31]. This notion is further supported by the observed variations of the linkages between component sugars and their substitution pattern. A rather similar situation is known from the $O$-antigens of LPS, because the antigenic diversity of LPS is reflected by a high compositional variability of the exposed $O$-antigens [32]. From the structural determinations of the S-layer glycan chains we conclude that the carbohydrate moieties of both S-layer glycoproteins and LPS resemble each other in length, chemical composition, and orientation on the cell surface [21]. Additionally a tripartite structure comprising a highly variable and a conserved carbohydrate part as well as a linkage region is realized in both cell surface molecules.
Whether these observations reflect a functional relationship of the glycans of both types of cell surface structures remains to be established.

To display the proposed structural similarities between S-layer glycoproteins and LPS the typical cell envelope profiles of Gram-positive and Gram-negative bacteria are illustrated (Fig. 1) [21]. To the outer membrane of the complex Gram-negative cell envelope LPS is bound. $O$-antigens of lipopolysaccharides, which are attached at the distal end of the core oligosaccharide [31-33], can form linear tri- or pentasaccharide repeating units, others consist of branched tetra- or hexasaccharides [34]. Most of the constituting sugars are hexoses, but unusual species such as 3,6-dideoxyhexoses and 2,4,6-trideoxyhexoses, amino sugars, hexuronic acids, and neuraminic acid have been found, too. Additionally, $O$-acetyl groups are present as immunodominant parts of the serologic epitopes [32]. Gram-positive bacteria (Fig. 1, left panel) possess a much simpler cell wall profile. In contrast to LPS no lipophilic anchor for the carbohydrate chains is present in 


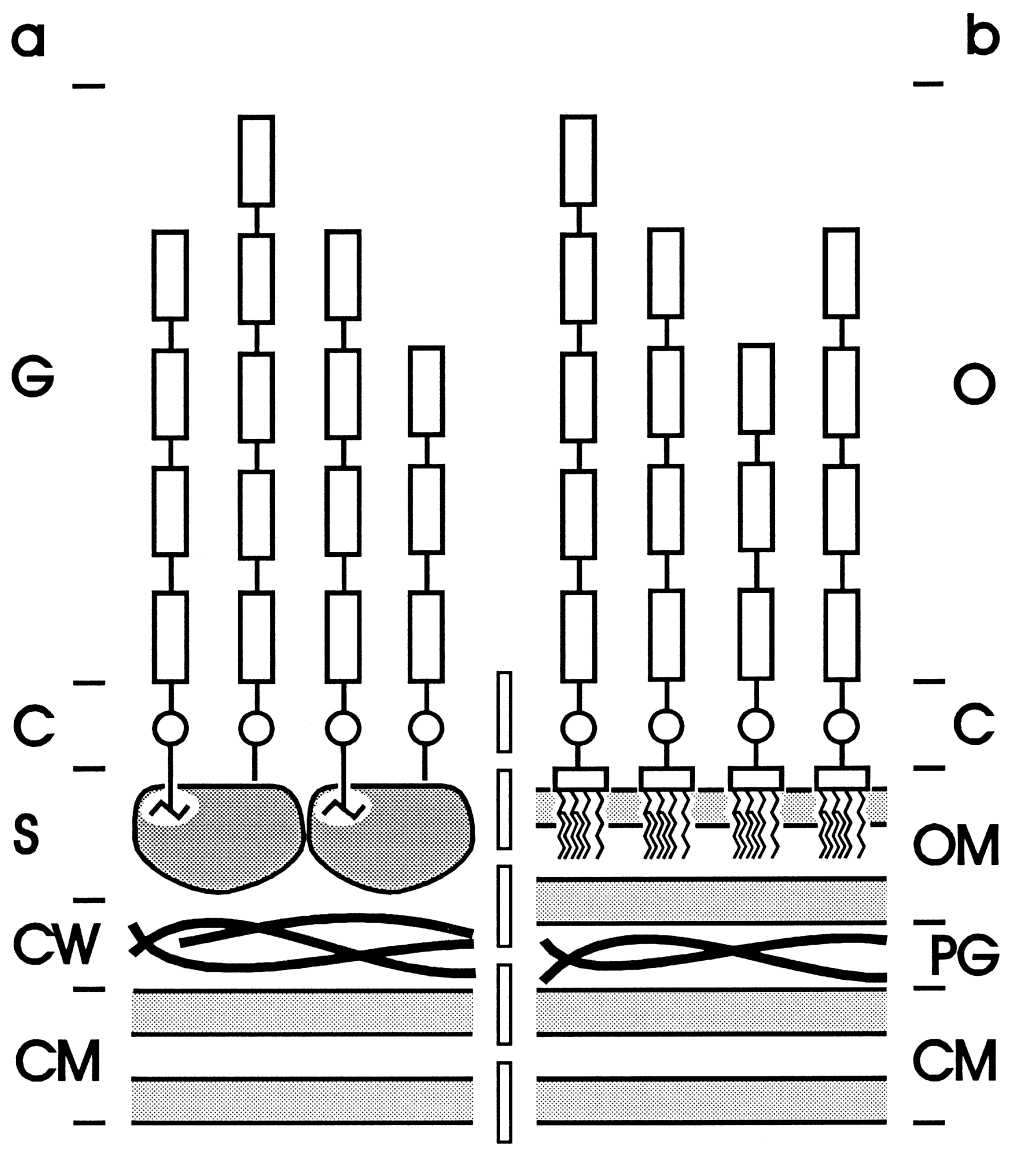

Fig. 1. Schematic drawing of the cell envelope composition of Gram-positive (a) and Gram-negative (b) bacteria underlining structural similarities between S-layer glycoproteins and LPS. C, core region; CM, cytoplasmic membrane; CW, cell wall; G, glycan chain; $\mathrm{O}, \mathrm{O}$-antigen; OM, outer membrane; PG, peptidoglycan (from [3]; with permission from R.G. Landes Comp.).

the Gram-positive cell envelope. Rather than bound to a lipid the S-layer glycans are covalently linked via a core to the respective S-layer protein.

\subsection{Glycosylation process in bacteria}

The discovery of glycosylated S-layers [1-5] made these structures particularly interesting for studying the biosynthesis of prokaryotic glycoproteins. Biosynthesis was studied in strain Th. thermosaccharolyticum E207-71 because of the high carbohydrate content (approximately 12\%) of its S-layer [18].

The isolation of cytoplasmatic sugar precursors was performed according to references [21,35-37]. For identification of nucleosidediphosphate activated precursors, including nucleosidediphosphate bound mono- and oligosaccharides and sugar-1-phosphate derivatives, samples were subjected to selective hydrolytic conditions and separated by cation-exchange HPLC or RP(C18)- HPLC. Liberated sugars were detected by HPAEC/PED either as monosaccharides or as alditol derivatives in the case of reducing sugars of activated oligosaccharides [21].

Based on the analysis of the precursors isolated from the biosynthetic pathway of the S-layer glycan, an assembly route for the hexasaccharide repeating unit of the S-layer glycan was proposed. The biosythesis of the hexasaccharide starts from the sugar-1phosphates of mannose, glucose, and galactose. These compounds are transferred into the corresponding nucleotide activated forms after reaction with nucleoside-5'-triphosphates [38]. This is GTP 
in the case of mannose and UTP in the case of the other sugars. Hence, TDP-Glc represents the precursor for the secondary glycosylnucleotides TDP-Rha and TDP-Qui. GDP-Man and UDP-Glc react with each other forming a GDP-activated disaccharide with mannose at the reducing end. In a next step galactose from UDP-Gal is transferred to the disaccharide completing the linear backbone structure of the hexasaccharide repeat. After the addition of TDP-Rha a branched tetrasaccharide is formed. Simultaneously a UDP-activated disaccharide is synthesized from UDP-Gal and TDP-Qui, which subsequently is linked to the rhamnose residue of the tetrasaccharide. The resulting hexasaccharide is GDP-activated and shows the same structure as the mature glycan does. No additional transient glycosylation of the repeating unit occurred as it was found in other archaeal (Methanothermus fervidus) [36] and bacterial ( $P$. alvei) S-layer glycoproteins [37].

In accordance with the data from the biosynthesis of the S-layer glycoprotein of $P$. alvei [37] in a final step the GDP residue of the completed glycan chain is replaced by a polyisoprenoid lipid, which might function as membrane anchor for the growing glycan chain before it is transferred to the nascent $\mathrm{S}$-layer polypeptide. Eventually, the biosynthesis of the S-layer glycoprotein is finished by the transfer of the complete glycan chain and the formation of the protein-carbohydrate linkage on the cell surface [2].

The lipid involved in the biosynthetic pathway of the S-layer glycoprotein of $P$. alvei was identified as $\mathrm{C}_{55}$-dolichol [37]. This lipid activated precursor contained three additional GlcNAc residues compared to the mature trisaccharide repeating unit. Whether GlcNAc is added before or after the transfer of the oligosaccharide to the lipid remains to be established. No GlcNAc was found in the intact glycoprotein, which indicated that the additional GlcNAc residues were removed during further processing [37].

For the preparation of biosynthetic carrier lipids of Th. thermosaccharolyticum E207-71 cells from the mid-logarithmic phase were metabolically labeled with $\left[{ }^{14} \mathrm{C}\right]$-glucose and extracted with hot ethanol $\left(70^{\circ} \mathrm{C}\right)$. Purification of the extract was achieved by a combination of TLC, DEAE-cellulose-, and Sephadex LH-20 chromatography. To discriminate between dolichol and undecaprenol the hydrolytic stability of the isolated products was tested [39].
Identification of appropriate compounds is currently performed by mass spectrometry.

Compared to the proposed biosynthesis route for the S-layer glycan from P. alvei CCM 2051 [37], in the case of Th. thermosaccharolyticum E207-71 two notable differences were observed. First, preliminary mass spectrometric results suggest a comparably short, potentially modified polyisoprenoid carrier lipid rather than a conventional $\mathrm{C}_{55}$-dolichol [unpublished data]. Second, although the complete hexasaccharide repeat occurs in the nucleosidediphosphatebound stage, only parts of this structure seem to be transferred to the lipid carrier [21].

\subsection{Conclusions}

Glycoproteins have been found in all groups of prokaryotic organisms [2]. The structures of prokaryotic glycoprotein glycans appear to be more diverse than those of eukaryotic ones. Considerable variability exists among the repeating unit structures, even within closely related strains of a species. Archaeal S-layer glycoproteins, so far investigated, contain predominantely rather short, $N$-linked glycans, and core structures seem to be absent. In bacteria long-chain glycoprotein glycans are attached to the S-layer polypeptide predominantely by $O$-glycosidic linkages. Some of them possess comparatively rare linkages via tyrosine such as D-galactosyl- $O$-tyrosine, and in short chains without repeats, D-glucosyl- $O$ tyrosine.

The proposed relationship between bacterial Slayer glycoproteins of Gram-positive bacteria and LPS of Gram-negative bacteria is based upon the following observations: (1) Sugar monosaccharides that were once thought to be unique to LPS have been identified as constituents of S-layer glycoprotein glycans. (2) S-layer glycans of the investigated bacteria show a tripartite structure and are composed of $O$-antigen like, variable carbohydrate chains strain-specifically built of identical repeats, that are covalently linked via a short core saccharide to the S-layer polypeptide.

More experiments are required to obtain conclusive results about the biosynthetic routes of S-layer glycoproteins fom bacteria. However, the current data indicate the occurrence of nucleotide-activated mono- and oligosaccharides, different carrier lipids, 
and trimming reactions. In future the biochemical approaches will be sustained by genetic analyses of the genes involved in the S-layer glycan biosynthesis. Since only a few well-characterized S-layer glycoproteins are presently known, many important questions about biosynthesis, molecular biology, and function of these cell surface structures remain to be answered.

\section{The paracrystalline surface-layer of Lactobacillus helveticus}

\section{Sylvie Lortal ${ }^{3}$}

The species Lactobacillus helveticus is widely used in dairy fermentations, in particular in Swiss type cheese like Emmental [40] and in Italian cheeses like Grana Padano. It has also been isolated from Bulgarian sour milk [41] and recently, Japanese authors highlighted the ability of some strains to produce fermented milk showing specific pharmacological activity (anti-hypertensive effect) [42]. Furthermore, free or immobilized cells of $L$. helveticus were used in bioreactors for the production of lactic acid from whey permeate [43]. Many fundamental and applied aspects of that species have been recently reviewed [44]. As far as the cell wall is concerned, the peptide moiety of the peptidoglycan (Lys-D-Asp), the nature of the teichoic acids (glycerol type) and of the neutral polysaccharides were determined [45]. The presence of an outermost proteinaceous layer was not emphasized in these studies, most probably as for the preparation of the cell wall fraction proteases and/or detergents have been used. The biochemical properties of the cell surface are of great importance in the interactions between L. helveticus and its environment (e.g., interaction with milk caseins or milk fat globules, resistance to bacteriophage attacks, adhesion to epithelium cells, immobilisation on solid substrates). The aim of this review is to highlight the recent data available on surface composition and surface properties of that species.

\subsection{Characterization of the Lactobacillus S-layer}

Masuda and Kawata in 1983 [46] were the first to

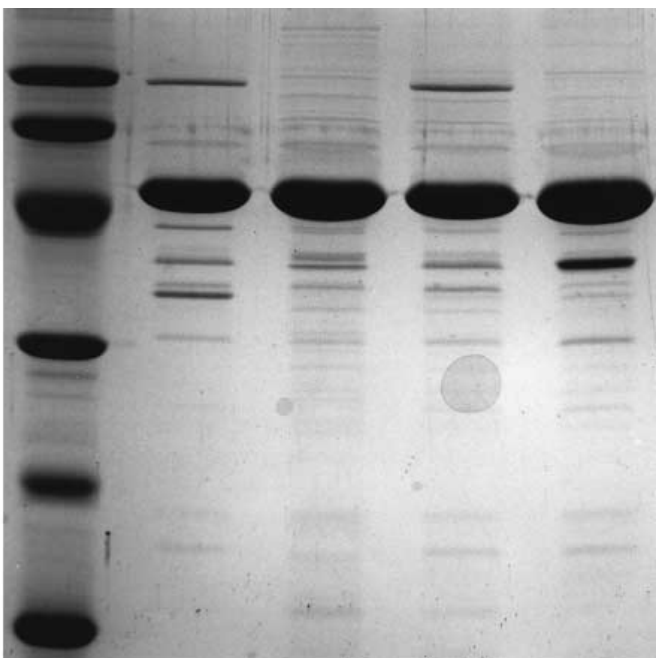

Fig. 2. SDS-PAGE of the total cell protein content of four different strains of $L$. helveticus showing the predominant S-layer protein band; on the left, molecular weight standard proteins $(\mathrm{kDa})$.

report the presence of an S-layer at the surface of many lactobacilli including $L$. helveticus [47] using SDS-PAGE and negative staining electron microscopy. More recently, freeze-etching experiments on intact cells and optical diffraction analyses of selfassembly products were performed which allowed the structural characterization of the S-layer proteins. The following parameters for the oblique lattices were determined: $a=4.1$ to $5.4 \mathrm{~nm}, b=9$ to $11 \mathrm{~nm}$ and $\gamma=76$ to $85^{\circ}$ (M. Sára, unpublished data; [48]). Interestingly, a "crazy paving appearance" of the S-layers was frequently observed. Up to date, the presence of S-layers was confirmed in more than 70 different strains, mainly by SDSPAGE analysis (as illustrated in Fig. 2). Since most of the strains investigated were isolated in different countries and were genetically not closely related, as shown by genomic DNA macrorestriction profiles [49], the presence of an S-layer can be regarded as a stable and general feature in L. helveticus, at least under laboratory conditions. No spontaneous disappearance of the S-layer was noticed, even during successive cultivation of the organisms in synthetic broth or in milk, or after keeping them for an extended period at lower temperatures $\left(4^{\circ} \mathrm{C}\right)$, additionally confirming its stability. The S-layer proteins usually reveal apparent molecular weights in the range of 50,000 (determined by SDS-PAGE) and were effi- 


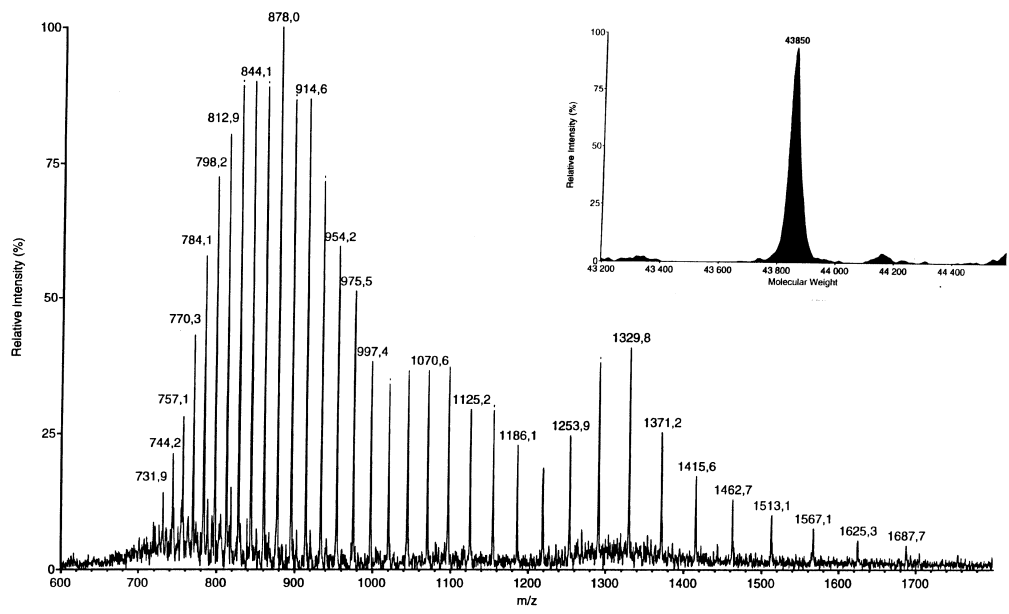

Fig. 3. ESI mass spectra of the purified S- layer protein of strain L. helveticus ISLC5 and reconstructed mass spectrum indicating an averaged mass value of 43,850 .

ciently and selectively extracted by a treatment with $5 \mathrm{M}$ lithium chloride ( $\mathrm{LiCl})$. Interestingly, a good survival (50 to $90 \%$ ) of the LiCl-treated cells was noted, when these cells were diluted in a new broth medium. During their growth they rebuilt a new Slayer in a random fashion [48]. The S-layer protein of strain ATCC 12046 was purified and the N-terminal sequence as well as the amino acid composition were determined, showing a large amount of hydrophobic amino acids and very few sulfur-containing amino acids [48]. The molecular weight was determined more precisely by ESI mass spectrometry, leading to a value of $43,533( \pm 10)$. In the same way, the S-layer proteins of eight other strains were extracted, characterized, and compared with strain ATCC 12046. Their N-terminal sequences were identical for the first nine amino acids and the determined molecular masses were in a narrow range between 43,533 ( \pm 10$)$ and 43,914 ( \pm 10$)$ [50] (Fig. 3). These results support the hypothesis of a high degree of similarity between the S-layer proteins of various strains of $L$. helveticus.

Recently, the S-layer protein encoding gene of strain L. helveticus CNRZ 892 was cloned and sequenced [51] revealing an ORF of 1,324 nucleotides with a deduced mature protein of 408 amino acids (EMBL accession number X92752). The relative conservation between the S-layer encoding genes of $L$. acidophilus and $L$. helveticus was also investigated [52]. The S-layer protein of L. helveticus CNRZ 892 was extracted and submitted to mass spectrometric analysis, leading to a value of 43,763 ( \pm 5 ) [unpublished data]. The molecular mass calculated from the cDNA-derived sequence data was 43,758 , which is in excellent agreement with the measured value. This correlation makes any post-translational modification of the S-layer protein of $L$. helveticus rather unlikely. Such modifications were previously assumed to occur as with the S-layer protein of L. helveticus ATCC 12046 [53] the DIG glycan detection reaction was positive and as two other lactobacilli species were previously reported to possess glycosylated S-layer proteins [10]. As briefly summarized in this paragraph, the biochemical and genetical characterization of the S-layer protein of $L$. helveticus was the object of intensive research during the last few years. However, it must be kept in mind that in this organism the S-layer represents only one particular component of the cell wall.

\subsection{The S-layer as a particular component of the cell wall}

As in Bacteria S-layers are usually not the exclusive cell wall component (additionally to peptidoglycan, teichoic acids/lipoteichoic acids, neutral polysaccharides) several questions arise: are S-layers the outermost component in L. helveticus, as it was observed for most other bacterial species? If this is the case, is it a homogeneous proteinaceous layer or are 


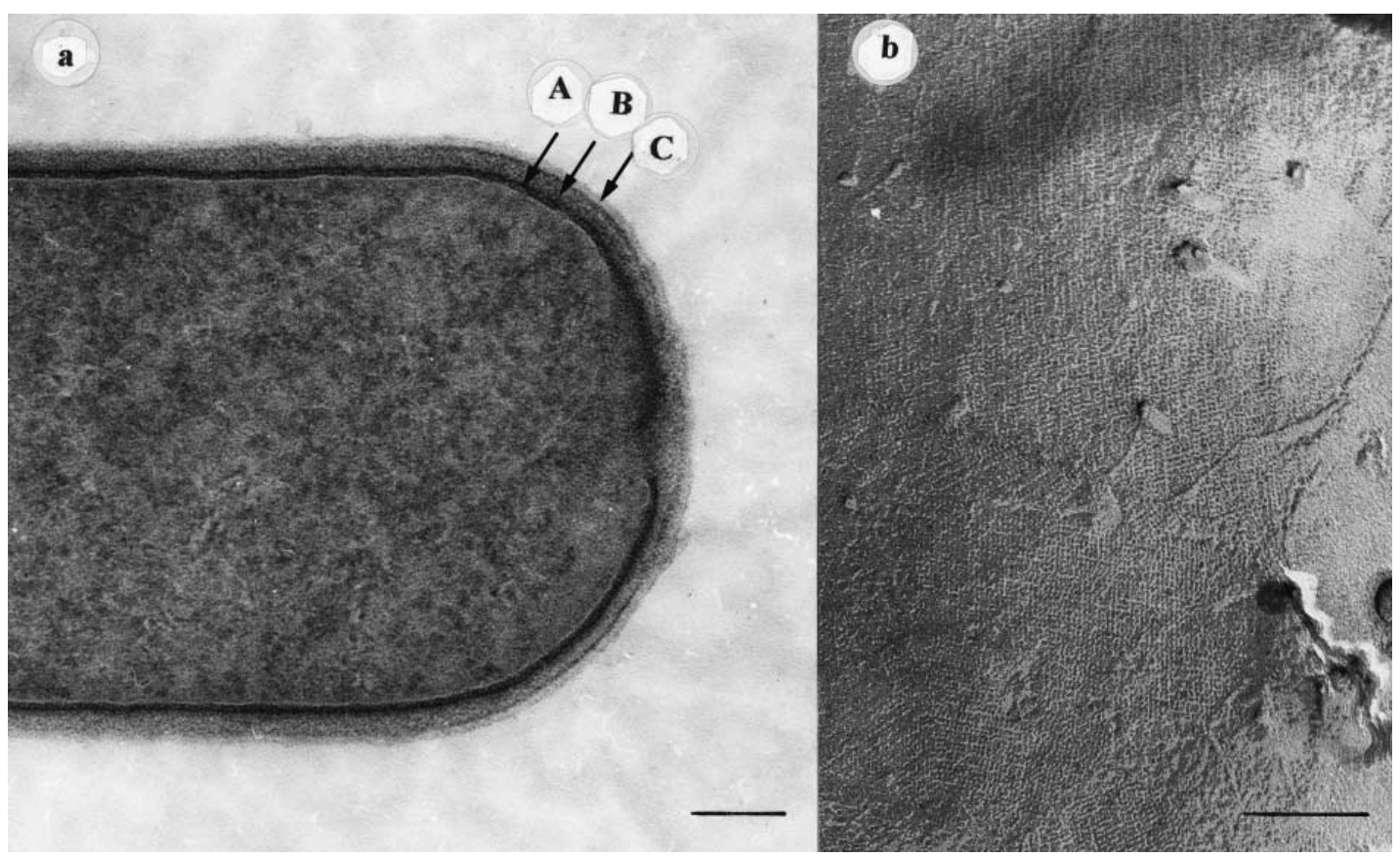

Fig. 4. Transmission electron microscopy (a) of whole cells of L. helveticus showing the three layered structure (A,B,C) of the cell wall, and the layer $\mathrm{C}$ corresponding to the S-layer [48,54]. Freeze-etched preparation (b) of the surface of $L$. helveticus showing the regular oblique lattice. Bars, $100 \mathrm{~nm}$.

other cell wall or membrane components locally intercalated in the paracrystalline structure? This question is essential for correlating any surface properties of $L$. helveticus with the presence of the S-layer. How thick is this S-layer? Further, which portion of the total dry weight of the cell wall is represented by the S-layer? What are the components of the underlying layer(s) and which bonds exist between them and the S-layer monomers? All these questions lead to the fundamental question: what is the role of the S-layer in L. helveticus?

Thin sections of L. helveticus ATCC 12046 revealed by transmission electron microscopy a three layered structure (Fig. 4a) [54]. The outermost layer (named C) represents the paracrystalline lattice, as was demonstrated by freeze-etching experiments (Fig. 4b) and it was assumed to be the S-layer [48]. In comparison to the total thickness of the cell wall of approximately $40 \mathrm{~nm}$ the thickness of the S-layer was estimated to be approximately $9 \mathrm{~nm}$. When cell walls were isolated by mechanical disruption, the S-layer was not lost (as verified by electron microscopic observations) and it was estimated to account for about $45 \%$ of the cell wall dry weight. The other components, such as the peptidoglycan, the neutral polysaccharides, and the teichoic acids, accounted for approximately $36 \%, 4 \%$, and $14 \%$, respectively. This means that the S-layer protein can be regarded as the major cell wall component in L. helveticus. Moreover, the S-layer protein represents about $14 \%$ of the total cellular proteins $[48,54]$.

The surface of intact cells of $L$. helveticus was investigated by X-ray electron spectroscopy (XPS) [53]. This physicochemical method provides the elemental composition (e.g., C,O,N,P content) and reveals the presence of functional groups (e.g., carboxyl or methyl groups) within a depth of 3-5 $\mathrm{nm}$ of the analysed surface. To the best of our knowledge, it was the first time that XPS was applied to an S-layer-carrying microrganism. In the case of $L$. helveticus the data correspond well to the outermost layer C (Fig. 4a). The surfaces of other microorganisms (e.g., bacteria, yeasts) were also investigated by XPS previously, leading to interesting observations [55].

The elemental composition of S-layers from two 
separate cultures of $L$. helveticus are summarized in Table 2. First, a comparison with data from the literature indicated that the ratio $\mathrm{N} / \mathrm{C}$ obtained for L. helveticus $(0.149)$ was higher than that commonly found for other lactobacilli (usually between 0.042 0.092). This could be explained by the presence of a proteinaceous S-layer. However, the most intriguing finding was that the outermost layer $\mathrm{C}$ of $L$. helveticus ATCC 12046 was indeed mainly composed of proteinaceous material, but the presence of phosphorus and of glycosidic bonds was clearly detected by XPS. These functional groups may have two origins: i) the S-layer protein could be glycosylated or phosphorylated but, as previously indicated, post-translational modifications can be considered unlikely; ii) other components are protruding the S-layer network, e.g., either teichoic or lipoteichoic acids (it would explain the phosphorus content as well as the glycosidic residues since glucose can substitute the glycerol moiety) and/or neutral polysaccharides. The presence of carbohydrate residues at the surface was also detected by another method previously. Thin sections of $L$. helveticus ATCC 12046 were submitted to Thiery staining (which is specific for 1,2diol groups) and a thin dark layer was clearly seen at the surface [54]. It was not possible to attribute the location of the staining reaction precisely to the phosphorus and carbohydrate residues. However, their presence clearly indicated that the surface of intact cells of $L$. helveticus ATCC 12046 contained not only the S-layer but additional material.

When cells were treated with $5 \mathrm{M} \mathrm{LiCl}$, layer $\mathrm{C}$ (i.e. the S-layer) disappeared completely, as did the prominent S-layer protein band in SDS-PAGE pro-

Table 2

Elemental composition of the surface of intact and $\mathrm{LiCl}$ treated cells of $L$. helveticus (atom fraction, \%, excluding hydrogen; average from two separate cultures) determined by X-ray electron spectroscopy (adapted form reference [53])

\begin{tabular}{lll}
\hline Element & Intact cells & LiCl-treated cells \\
\hline $\mathrm{C}$ & 60.11 & 57.79 \\
$\mathrm{O}$ & 30.42 & 35.23 \\
$\mathrm{~N}$ & 8.95 & 5.93 \\
$\mathrm{P}$ & 0.52 & 1.04 \\
$\mathrm{~K}$ & $\mathrm{D}$ & BLD \\
$\mathrm{S}$ & $\mathrm{D}$ & BLD \\
\hline
\end{tabular}

Abbreviations: D, detected, but too low to be considered quantitatively; BDL, below detection limit. files. The morphology of the cells was not damaged by this treatment. In order to investigate the composition of the intermediate layer $\mathrm{B}$, and for comparison with intact cells, LiCl-treated cells were submitted to XPS analysis. As indicated in Table 2, the extraction of the S-layer induced a drastic change in the surface composition, resulting in particular in modifications of the ratios N/C, O/C, P/C. Further, analysis of the peaks provided the composition of the functional groups of the sample. The data indicate that the underlying layer (layer B) is composed of a mixture of peptidoglycan, teichoic acids, and neutral polysaccharides (for details see [53]). Upon $\mathrm{LiCl}$ treatment to remove the S-layer the newly generated surface was shown to be strongly negatively charged. This was demonstrated by labelling with polycationic ferritin [48]. From this observation the conclusion can be drawn that just below the S-layer there is a layer highly enriched in peptidoglycan and teichoic acids.

\subsection{Conclusions and hypotheses about the physiological role(s) of S-layers}

Since its first desciption 15 years ago, the S-layer protein of $L$. helveticus has been isolated from the cells, structurally and chemically characterized [by electron microscopy and X-ray electron spectroscopy (XPS)], and the encoding gene was cloned and sequenced. However, as far as the potential role(s) of the S-layer are concerned, the data are rather scarce. It was observed that the S-layer protein did not protect the cells against the lytic action of lysozyme or mutanolysine [48]. The S-layer protein was resistant to trypsin in situ but became sensitive when it was extracted. In contrast, pronase was active against intact cells of $L$. helveticus, leading to a significant proteolysis of the S-layer protein [unpublished data]. These results did not support the concept of a protective role of this layer.

Regarding the functional role(s) of the S-layer of L. helveticus several hypotheses can be put forward: i) to mask the underlying strongly negative charge of the surface (allowing improved interaction with the environment); ii) to trap useful minerals or small components by charge interactions (role in nutrition?); iii) to act as cation exchanger since the cells remain viable and can even grow at $\mathrm{pH}$ values below 
4.0 ; iv) to interact with other surfaces, (adhesion to epithelium cells or to solid support). For exemple, the S-layer of $L$. crispatus was shown to bind to collagen [56]. In contrast, however, it was observed that the chemical removal of the S-layer of $L$. acidophilus did not influence in vitro the adhesion to Caco-2 cells [57]. Furthermore, despite the high degree of similarity which was demonstrated among S-layers of various strains of $L$. helveticus, these strains can differ significantly in their surface properties (as was indicated by partition assays and electrophoretic mobility measurements; unpublished data). The fact that the surface of $L$. helveticus is not composed solely of the S-layer will make it rather difficult to attribute a particular function to this protein. The recent molecular biological approaches providing the sequence of the S-layer gene and its localisation on the genome [51] will allow the isolation of S-layer-free mutant strains of $L$. helveticus in the near future. This might help to solve the fundamental questions about the functional role(s) of S-layers in this organism.

\section{Polyglutamate surface polypeptides in Bacteria and Archaea}

\author{
Helmut König ${ }^{3}$, Ruth Niemetz
}

Beyond the major cell wall components of Bacte- ria and Archaea prokaryotes produce capsular exopolymers varying widely in their chemical composition. The majority of the exopolymers are polysaccharides, but also exopolypeptides composed of only one type of amino acid, namely glutamate [58-64], were formed. In Bacteria the glutamate residues possess the $\mathrm{L}$ - or D-configuration. D-glutamic acid residues are usually $\gamma$-linked, while L-glutamine residues are $\alpha$-linked. In the case of Bacillus anthracis they play an important role in the pathogenesis. Recently, in alkalophilic halococci also a poly- $\gamma$-glutamine cell wall polymer was discovered, which is described here and compared with the well known exopeptides of Bacteria.

\subsection{Occurrence of polyglutamate exopeptides in Bacteria}

\subsubsection{Distribution}

The cell walls of various bacteria can possess unusual high contents of glutamic acid in their cell wall preparations, which were found to originate from a capsular polyglutamic acid polymer [58-64]. The capsule of Bacillus anthracis surrounds the cells as a uniform layer [65]. Polyglutamyl capsules have been found in several bacteria mainly assigned to the Gram-positive phylogenetic branch (Table 3). The exopolypeptides produced by bacteria are linear polymers. Most of the information about exopeptide capsules has been obtained from analyses of the

Table 3

Microorganisms with polyglutamate exopeptides

\begin{tabular}{llll}
\hline Domain/Species & Configuration & Linkage & Reference \\
\hline Bacteria & $\mathrm{D}$ & $\gamma$ & {$[58,61]$} \\
Bacillus anthracis & $\mathrm{D}$ & $\gamma$ & {$[60,66]$} \\
Bacillus licheniformis & $\mathrm{D}$ & $\gamma$ & {$[62]$} \\
Bacillus megaterium & $\mathrm{D}$ & $\gamma$ & {$[59]$} \\
Bacillus subtilis & $\mathrm{L}$ & $\alpha$ & {$[64]$} \\
Flexithrix dorotheae & $\mathrm{L}$ & $\alpha$ & {$[63]$} \\
Mycobacterium tuberculosis & $\mathrm{D}$ & $\gamma$ & {$[64]$} \\
Planococcus halophilus & $\mathrm{D}$ & $\gamma$ & {$[64]$} \\
Sporosarcina halophila & $\mathrm{L}$ & $\alpha$ & {$[64]$} \\
Xanthobacter autotrophicus & $\mathrm{L}$ & $\alpha$ & {$[64]$} \\
Xanthobacter flavus & & & {$[\mathrm{C}$} \\
Archaea & $\mathrm{L}$ & $\alpha$ & {$[80] ;$ König, unpublished] } \\
Natronococcus occultus & $\mathrm{L}$ & $\alpha$ & \\
Halococcus turkmenicus & & &
\end{tabular}


poly- $\gamma$-glutamate polymer of bacilli, especially Bacillus anthracis, which has been reviewed recently [58].

Cell wall preparations of Mycobacterium tuberculosis contain a polyglutamyl polymer, which is at least partly amidated [63] The polypeptide constitutes up to $8 \%$ of the cell wall preparations. It has a molecular mass of about 35,000 , corresponding to more than 200 glutamine residues. In contrast to the bacilli it consists of $\alpha$-linked L-glutaminyl residues.

In four other bacterial genera polyglutamate exopeptides have been found. Strains of Xanthobacter and Flexithrix contain an $\alpha$-L-glutaminyl polymer, while Sporosarcina halophila and Planococcus halophilus form a $\gamma$-D-glutamyl exopeptide [64]. In Xanthobacter autotrophicus the polymer formation depends on the growth conditions. No polymer is formed with $\mathrm{N}_{2}$ as sole nitrogen source. The sheathed gliding bacterium Flexithrix dorotheae contains very little murein of the meso-diaminopimelic acid (mDpm)-direct type in the cell walls, but large amounts of polyglutamine [64]. The glutamine residues are $\alpha$-linked. The structure of the exopolymers found in Xanthobacter and Flexithrix resemble that of Mycobacterium tuberculosis, but they are amidated in addition.

In general it seems that in Bacteria the $\alpha$-linked polymers composed of glutamyl or glutaminyl residues possess the L-configuration, while in the case of the $\gamma$-linked exopeptides the glutamic acid residues have the $\mathrm{D}$-configuration. The poly- $\gamma-\mathrm{D}-$ glutamyl polymers occur in the phylogenetically related genera Bacillus, Sporosarcina, and Planococcus.

\subsubsection{Biosynthesis}

Capsulation is initiated in the stationary phase. Polymerisation continues in the presence of tetracycline and chloramphenicol and does not take place at the ribosomes [58,65-71]. The average molecular weight of the Bacillus licheniformis polymer was 173,000. Polyglutamate productivity was greatest around $125 \mathrm{~h}$, while growth occurred mainly during the first $24 \mathrm{~h}$ [66]. Polyglutamic acid synthetase activity was demonstrated in disrupted cells of Bacillus licheniformis [67,70,71]. Not D-glutamic acid, but L-glutamic acid was the precursor of the D-glutamic acid residues in the exopeptide. A membrane bound polyglutamic acid synthetase complex catalyzed glutamate activation, racemization, and polymerization. The product of polyglutamyl synthetase was poly- $\gamma$ D-glutamic acid. The in vitro synthesized polymer had a molecular weight range from 172,000 to 363,000 , while the native polymer had a greater polydispersity ranging from 84,000 to $1,150,000$. The following biosynthetic pathway was suggested (67):

Reaction 1 :

$$
\mathrm{L}-\mathrm{Glu}+\mathrm{ATP} \rightarrow \gamma-\mathrm{L}-\mathrm{Glu}-\mathrm{AMP}+\mathrm{PP}_{\mathrm{i}}
$$

Reaction 2 :

$$
\gamma-\mathrm{L}-\mathrm{Glu}-\mathrm{AMP} \rightarrow \gamma-\mathrm{x}-\mathrm{Glu}-\mathrm{S}-\text { protein }+\mathrm{AMP}
$$

\section{Reaction 3 :}

$$
\gamma-\mathrm{x}-\mathrm{Glu}-\mathrm{S}-\text { protein } \rightarrow(\gamma-\mathrm{D}-\mathrm{Glu})_{\mathrm{n}}-\mathrm{S}-\text { protein }
$$

Reaction 4 :

$$
\begin{aligned}
& (\gamma-\mathrm{D}-\mathrm{Glu})_{\mathrm{n}}-\mathrm{S}-\text { protein }+ \text { acceptor } \rightarrow \\
& (\gamma-\mathrm{D}-\mathrm{Glu})_{\mathrm{n}}-\text { acceptor } \\
& \mathrm{x}=\mathrm{L} \text { or } \mathrm{D} .
\end{aligned}
$$

\subsubsection{Molecular biology}

Genes involved in polyglutamyl synthesis are located on the chromosome in the case of Bacillus licheniformis, while in Bacillus anthracis capsule synthesis is encoded by the $95-\mathrm{kb}$ plasmid pXO2 [58,71-73]. Three genes have been identified and the capB, capC and cap $A$ gens encode for proteins with molecular weights of 44,000, 16,000, and 46,000, respectively [74]. Each gene had its own promotor and all were transcribed in the same direction.

\subsubsection{Biological activity}

Bacillus anthracis causes anthrax in humans and animals and the capsule is one of the virulence factors $[58,75]$. Mutants without a capsule become avirulent. The nonvirulent $\mathrm{R}$ type can be used as a vaccine. Peptides obtained by partial acid hydrolysis were assayed for reactivity with rabbit antisera produced against the polypeptide. The maximum size for antibody recognition was six residues of D-glutamic acid. [76,77]. 


\subsection{Occurrence of polyglutamte exopeptides in Archaea}

\subsubsection{Distribution}

Extremely halophilic coccoid Archaea have been placed into the genera Natronococcus and Halococcus. The archaeon Natronococcus occultus survives optimally in extremly alkaline biotopes with a $\mathrm{pH}$ value between 9.5 and 10.0 and a salt concentration around $3.5 \mathrm{~mol}^{-1}$ [78], while Halococcus prefers more neutral $\mathrm{pH}$ values. The cell wall polymer of Halococcus morrhuae is a complex heteropolysaccharide [79], whereas a polyglutamate glycoconjugate forms the cell wall polymer of Natronococcus occultus [Niemetz, R., Kärcher, U., Kandler, O., Tindall, B., König, H. Eur. J. Biochem., submitted]. It differs from all known archaeal cell wall structures [80] such as pseudomurein, methanochondroitin, heterosaccharides or S-layer (glyco-)proteins in its chemical composition and the linkage mode of its oligosaccharides.

\subsubsection{Chemical composition}

The chemical composition of the isolated cell wall polymer of Natronococcus occultus is shown in Table 4. The hydrolysate of the isolated cell wall polymer contained only one amino acid, namely glutamic acid, the two amino sugars glucosamine and galactosamine, the two uronic acids galacturonic acid and glucuronic acid, and the hexose glucose. Glutamate possessed the L-configuration, while all other constituents occurred in the D-configuration.

\subsubsection{Structure of the peptide}

After partial acid hydrolysis a $\gamma$-glutamyl dipeptide was obtained, while an $\alpha$-glutamyl dipeptide could

Table 4

Chemical composition of the cell wall polymer of Natronococcus occultus

\begin{tabular}{ll}
\hline Compound & Molar ratio \\
\hline L-Glu & 5.2 \\
D-GlcNAc & 7.2 \\
D-GalNAc & 1.0 \\
D-GalA & 7.5 \\
D-GlcA & 0.5 \\
D-Glc & 0.3 \\
\hline
\end{tabular}

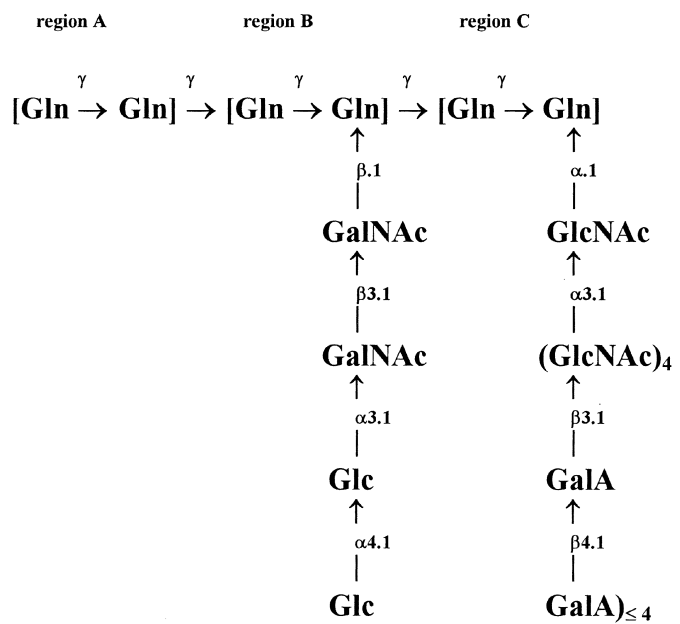

Fig. 5. Proposed structure of the repeating units (A-C) of the cell wall polymer of Natronococcus occultus. The exact distribution of the repeating units was not determined.

not be isolated. After removal of the carbohydrates with hydrofluoric acid a soluble polymer was obtained, which consisted only of glutamic acid residues. The length of the polyglutamic acid chain was determined to be about 60 monomers, which occurred at least partially amidated.

\subsubsection{Structure of oligosaccharides}

In the cell wall polymer the glucosamine, glucuronic acid and glucose residues possessed the $\alpha$-conformation and the galactosamine and galacturonic acid residues occurred in the $\beta$-conformation. The amino sugars were 1,3-linked, while the galacturonic acid, glucuronic acid and glucose residues possessed a 1,4-linkage.

Two types of oligosaccharides were removed from the polyglutamine backbone by hydrazinolysis. One oligosaccharide consisted of an $\mathrm{N}$-acetyl-glucosamine pentasaccharide at the reducing end and a galacturonic acid hexasaccharide at the non-reducing end (Fig. 5). There was no indication for an alternating sequence of the glucosamine and galacturonic acid residues as it is the case with hyaluronic acid or chondroitin. The second oligosaccharide had an $N$-acetyl-galactosamine disaccharide at the reducing end and a maltose unit at the non-reducing end. 


\subsubsection{Linkage of the oligosaccharides to the peptide chain}

Since the glutamic acid residues are linked via their $\gamma$-carboxylic groups the amino sugars at the reducing end of the two oligosaccharides must be linked to the $\alpha$-carboxylic group. The corresponding oligomeric fragments were isolated from partial acid hydrolysates.

\subsubsection{Proposal of the structure of the cell wall polymer}

The cell wall polymer of Natronococcus occultus is formed by a poly- $\gamma$-L-glutamine chain of about 60 residues to which two different types of heterosaccharides are linked via $\mathrm{N}$-amide linkages to the $\alpha$-carboxylic group of the glutamine residues. One heterosaccharide consists of an $\mathrm{N}$-acetylgalactosamine disaccharide and a maltose unit. Since the molar ratio of galactosamine and glucose was 3:1 in the intact polymer additional oligosaccharides should occur, which may consist of only galactosamine, but lack the glucose residues at the non-reducing end. The second heterosaccharide is composed of an $\mathrm{N}$-acetylglucosamine pentasaccharide and up to six galacturonic acid residues. In average, every second glutamine residue is substituted by an oligosaccharide. The heterosaccharides together with the glutamyl dipeptide form the repeating units of the cell wall polymer (Fig. 5A-C). Most probably, some of the glutamyl dipeptides do not carry oligosaccharides. The exact distribution of the two oligosaccharides was not determined. The isolation and analysis of one fragment after partial acid hydrolysis provided evidence that at least three glucosamine residues-containing heterosaccharides, linked to glutamyl dipeptides, are connected in series. A proposal of the structure of the intact cell wall polymer of Natronococcus occultus is shown in Fig. 5. The molar ratio of the components indicates that three glucosamine-containing oligosaccharides per one galactosamine-containing oligosaccharide are linked to $\gamma$-glutaminyl-glutamine dipeptides. The carboxylic groups of the galacturonic acid residues may function as a chelating agent for cations in the halophilic environment.

In contrast to bacterial genera the glutamic acid residues of the cell wall polymer of the archaeon Natronococcus occultus have exclusively the L-config- uration and are connected via the $\gamma$-carboxylic group. So far D-amino acids have not been found in cell walls of Archaea [80]. Only the cell wall polymer of the extremely halophilic archaeon Halococcus turkmenicus, which was recently investigated in our group, also possessed an L- $\gamma$-polyglutamic acid polymer, to which oligosaccharides are linked [80]. A main difference to the bacterial polyglutamate peptides is the linkage mode of oligosaccharides in the case of the natronococci, which are connected to the $\alpha$-amide group of glutamine residues. Usually, $\mathrm{N}$-linked oligosaccharides of bacterial and archaeal cell wall glycoconjugates are linked via galactosamine, glucose or rhamnose to the $\beta$-amide group of asparagine $[3,80]$. Therefore, their exopeptides represent a novel type of naturally occurring glycoconjugate.

\section{Contributions of mass spectrometry to microbial S-layer research}

Günter Allmaier ${ }^{3}$, Maria Dorner, Paul Messner

Since the early studies on peptides by Biemann and co-workers [81] in the early 1960s, mass spectrometry (MS) has been considered an extremely promising technique for the characterization and structural elucidation of various biopolymers. However, the impact of mass spectrometry has, until recently, been very limited in the life sciences. This was mainly caused by the limited relative molecular mass range amenable to MS analysis and the great complexity of the instrumentation. However, in the early 1980s, one method was developed that allowed the mass spectrometric analysis of much larger molecules $(\geq 10,000)$ than was hitherto possible. Large, thermally labile biopolymers as protein or carbohydrates could be desorbed and ionised without the extensive chemical derivatisation required in more classical mass spectrometric techniques, such as electron impact and chemical ionisation. This technique, Californium-252 plasma desorption mass spectrometry (PDMS) combined with a non-scanning ion analyser system, has been known since 1974 [82], but only after the recording of an intact protein as insulin [83] its tremendous potential for biopolymer studies 


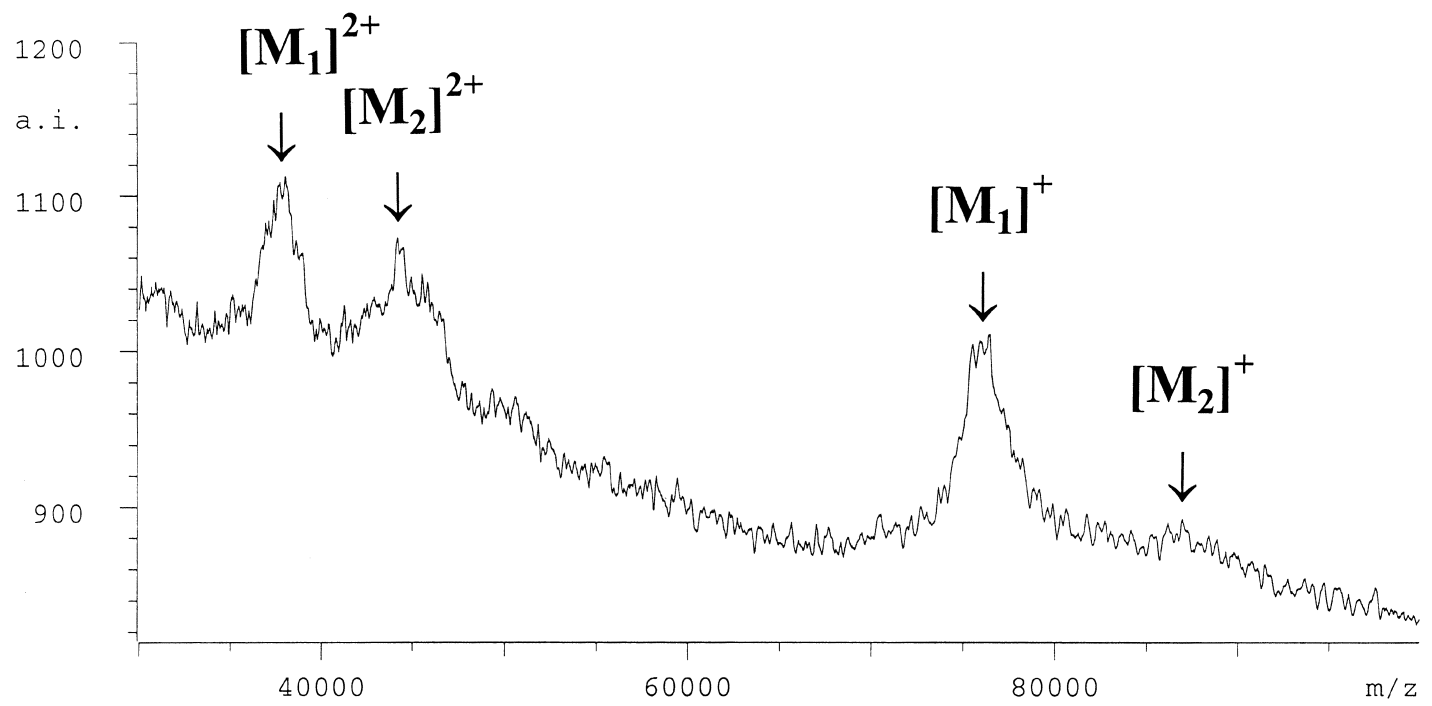

Fig. 6. Positive-ion MALDI mass spectrum of S-layer protein/glycoprotein mixture isolated from Clostridium thermosaccharolyticum strain E207-71. The spectrum (sum of 10 laser pulses) was obtained on a linear time-of-flight instrument at $30 \mathrm{kV}$ accelerating voltage with an nitrogen laser at $337 \mathrm{~nm}$. $\alpha$-Cyano-4-hydroxy cinnamic acid was used as matrix and preparation was done as described [88]. [ $\left.\mathbf{M}_{1}\right]^{\mathrm{n}+}$ $(n=1-3)$ denotes the main S-layer protein ions and $\left[\mathrm{M}_{2}\right]^{\mathrm{n}+}(n=1-2)$ corresponds to highly glycosylated forms. The relative molecular mass for $M_{1}$ was measured as 75,620 (determined from the $\mathrm{m} / \mathrm{z}$ values of $\left[\mathrm{M}_{1}\right]^{+},\left[\mathrm{M}_{1}\right]^{2+}$ and $\left[\mathrm{M}_{1}\right]^{3+}$ ions).

was really understood. During the 1980s, PDMS and further fast atom bombardment mass spectrometry (FABMS) gradually became accepted in protein and carbohydrate chemistry. Both areas of applications required high sensitivity and a very wide relative molecular mass range. Only PDMS could provide low picomole sensitivity at least for proteins below 30,000 molecular mass. The demand for increased sensitivity (subpicomole range) and for a high mass range was satisfied by the end of the decade with the discovery of two new desorption/ionisation techniques combined with improved ion analyser (timeof-flight and quadrupole systems), matrix-assisted UV laser desorption ionisation mass spectrometry (MALDIMS) [84,85] and electrospray ionisation mass spectrometry (ESIMS) [86]. With these methods, sensitivities in the femtomole range have been obtained. Their upper molecular mass limits are not yet known, but they are well beyond 1,000,000 and 200,000 , respectively. To summarize these developments, the early 1980 s were the time when mass spectrometry was a promising tool for the analysis of peptides and proteins, carbohydrates and glycopep- tides, as well as oligonucleotides. In the late 1980s and early 1990s it became a sophisticated and useful technique [87] and it is believed that at the end of the century MS will be a fully integrated and indispensable method in a laboratory working with biopolymers. This article will give a description of the type of information that can be obtained by MS of S-layer (glyco)proteins and S-layer related glycoconjugates and examples of the integration of various MS techniques in microbial S-layer research.

\subsection{Mass spectra of intact glycoproteins and proteins}

The mass spectra of glycoproteins and proteins are dominated by ions corresponding to protonated $[\mathrm{MH}]^{+}$or multiply protonated molecules $[\mathrm{MnH}]^{\mathrm{n}+}$. If sodium or potassium ions are present, $[\mathrm{MH}]^{+}$may be replaced with $[\mathrm{MNa}]^{+},[\mathrm{MK}]^{+},[\mathrm{M}+2 \mathrm{Na}-\mathrm{H}]^{+}$or $[\mathrm{M}+\mathrm{Na}+\mathrm{K}-\mathrm{H}]^{+}$. The latter two are especially disadvantageous because relative molecular mass assignment becomes difficult and because the distribution of the ion current on different molecular ion species 
reduces the signal-to-noise ratio. The presence of alkali salts in the samples must therefore be reduced to a minimum.

\subsubsection{MALDI mass spectrometry}

In MALDI mass spectra generally, the most intense signal is the singly charged molecular ion. Additionally, doubly and triply charged molecular ions as well as sometimes singly and multiply charged cluster ions appear. Fig. 6 shows a typical MALDI spectrum from a purified S-layer protein/glycoprotein mixture. MALDIMS was used to verify the molecular weight (determined by polyacrylamide gel electrophoresis) and purity of the sample, which was soluble only in $5 \mathrm{M}$ guanidine hydrochloride. By applying a special sample preparation technique including an extensive washing procedure to remove the salt [88] for the first time the single charged $\left[\mathrm{M}_{1}\right]^{+}$of an intact S-layer protein was determined with high accuracy $( \pm 0.2 \%)$. The amount of protein material in this molecular weight range necessary to acquire the MALDI mass spectrum successfully is in the low nanogram range.

\subsubsection{ESI mass spectrometry}

ESI mass spectra are created from a dilute solution of the protein (typically a water-organic solventorganic acid mixture) by creating a spray of fine, highly charged droplets in the presence of a strong electric field. The droplet evaporation results in ions with very high charge states, on average one positive charge per 1,000, and the mass spectra of proteins contain a series of peaks differing by one charge in a relative low $\mathrm{m} / \mathrm{z}$ range. Because of the multiple charging effect, a mass analyser with a limited mass range as e.g., a quadrupole mass spectrometer can be applied to measure large proteins. A typical application of the ESI technique is the verification of proteins with good solubility characteristics (no detergents or high buffer salt contents are allowed) as the isolated S-layer proteins of dairy propionibacteria [89]. The results were consistent with the data obtained by gel electrophoresis and demonstrate that ESIMS can be applied straightforward with high mass accuracy but not in case of insoluble or weakly solubilized S-layer (glyco)proteins.

\subsection{Mass spectra of glycoconjugates}

\subsubsection{PD and ESI mass spectrometry}

The first step in acquiring information on a particular glycoconjugate is the determination of the relative molecular mass by mass spectrometry. The positive-ion mass spectra as, for example, in case of the tyrosine-linked carbohydrate moiety isolated from the S-layer glycoprotein of Thermoanaerobacter (formerly Clostridium) thermohydrosulfuricus [90] or the heterosaccharide of the S-layer glycoprotein of Methanothermus fervidus [6] are dominated by sodiated molecular ions due to the affinity of these compound class to alkali ions. Negative-ion mass spectra containing deprotonated molecular ions can be obtained for amino acid carrying carbohydrates, too. ESI mass spectra of such compounds exhibit similar information. By using PDMS or ESIMS it is possible to determine the relative molecular mass with an accuracy of $0.1-0.01 \%$ depending mainly on instrumental parameters.

\subsubsection{MALDI mass spectrometry}

To study large (relative molecular mass $>4,000$ ) glycoconjugates with any tagging step the method of choice for molecular weight and/or heterogeneity determination is MALDIMS due to unsurpassed sensitivity and mass range. The exact relative molecular mass of an $O$-glycosidically linked glycan chain isolated from the S-layer glycoprotein of Thermanaerobacter thermohydrosulfuricus [14] could for the first time be determined by reflector MALDIMS with a mass accuracy $\leq 0.09 \%$. It was also possible to demonstrate the extremly broad (spanning a mass range of 4,000) heterogeneity of this carbohydrate moiety and to determine the exact number of disaccharide repetitive units present in this structure, which was only possible by MS at the amount of material applied.

\subsubsection{Fragmentation of glycoconjugates inside the mass spectrometer}

In addition to information on relative molecular mass, the formation of structurally informative fragment ions is one of the important features of MS. Among the three desorption/ionisation methods discussed here, fragment ions useful for the characterization of S-layer relevant glycoconjugates are ob- 


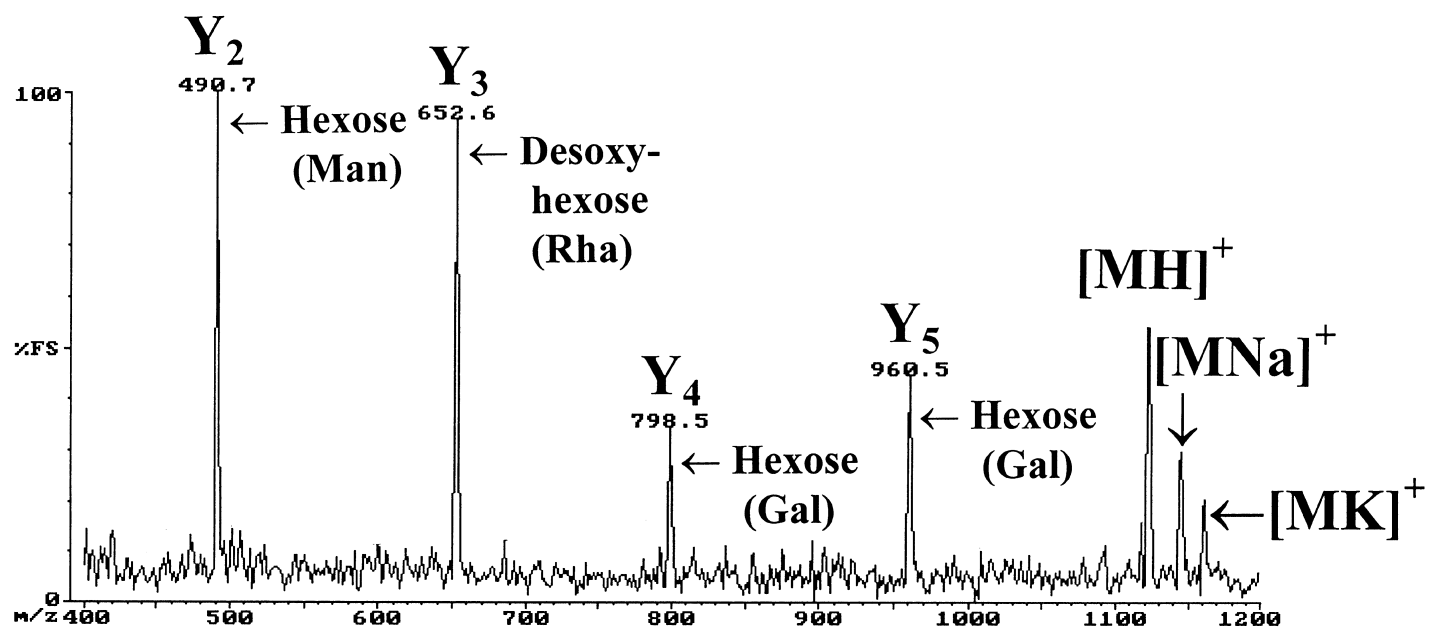

Fig. 7. Positive-ion ESI mass spectrum of the tyrosine-linked carbohydrate moiety [ $\beta$-D-Galf-( $1 \rightarrow 3)-\alpha-\mathrm{D}-\mathrm{Gal} p-(1 \rightarrow 2)-\alpha-\mathrm{L}-\mathrm{Rh}$ ap- $(1 \rightarrow 3)-\alpha-$

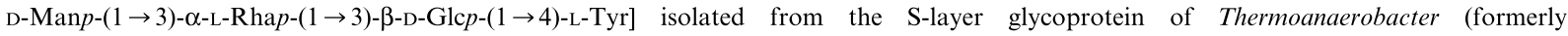
Clostridium) thermohydrosulfuricus strain S102-70 [90]. The spectrum was obtained on a quadrupole instrument with a dedicated ESI source with an increased cone voltage $(90 \mathrm{~V}$ ). The sample was dissolved in water/acetonitrile (containing $1 \%$ formic acid and introduced via loop injection. $[\mathrm{MH}]^{+}$denotes the protonated molecular ion and $[\mathrm{MX}]^{+}(\mathrm{X}=\mathrm{Na}$ or $\mathrm{K})$ cationised molecular species. The nomenclature of the fragment ions $\left(\mathrm{Y}_{\mathrm{n}}\right)$ corresponds to that of Domon and Costello [92] (Man, mannose; Gal, galactose; Rha, rhamnose).

tained spontaneously by PDMS or by in-source collision induced dissociation (CID) in case of ESIMS and post source decay (PSD) combined with MALDIMS. For large glycoconjuates (relative molecular mass $>2,500)$ these fragment ions are not very informative and not of practical use, whereas for small molecules they may yield important structural information especially in combination with other analytical methods [e.g., nuclear magnetic resonance spectroscopy (NMR)]. In case of the tyrosine-linked carbohydrate moiety (hexasaccharide) isolated from the S-layer glycoprotein of Thermoanaerobacter thermohydrosulfuricus S102-70 PDMS with sufficent material (ten times more necessary than for relative molecular mass determination) generated high energy CID-like fragment ions. The detailed interpretation of those PDMS data combined with NMR and monosaccharide/amino acid data provided the complete structure of this important glycopeptide containing a new $O$-glycosidic linkage [90]. The same glycopeptide was analysed by ESIMS applying insource CID (a prerequisite is a highly purified compound) resulting in a mass spectrum as shown in Fig. 7. A number of intense fragment ions $\left(\mathrm{Y}_{\mathrm{n}}, n=1-5\right.$, low enenergy CID fragmentation) corresponding to the subsequent loss of monosaccharide moieties from the protonated molecular ion could be observed, but only the combination of the ESIMS, NMR and linkage analysis data can give the detailed structure. For the study of the biosynthesis of glycan structures present in S-layer glycoproteins it is necessary to isolate and characterize in detail sugar nucleotides which are present only in low amounts. First attempts have been made to apply PSD combined with MALDIMS for the structural elucidation of glycosyl esters of nucleoside pyrophosphates. A large number of fragment ions especially relevant to the glycosyl moiety have been detected by PSD MALDIMS at the low picomole level [91] and will help to shed some light on the biosynthesis of $O$-linked oligosaccharides of S-layer glycoproteins.

\subsection{Conclusions and perspectives}

PDMS, MALDIMS and ESIMS have, in the last years, brought mass spectrometry into the field of glycoconjugate/protein chemistry and have effectively demonstrated the potential of MS in S-layer research. The sensitivity of all the mentioned mass spectrometric methods is adequate at least for protein studies and, especially with the recently developed desorption/ionisation techniques, so high that MS, for the first time, is ahead of the traditional isolation/purification and analytical procedures. 
Both techniques (MALDIMS and ESIMS) are inherently sensitive methods whose sensitivity, in practice, is limited mainly by our ability to handle very small quantities of material without severe loss prior to MS analysis. A key to successful and rapid mass spectrometry of various biopolymers will be a convenient means for coupling various chromatographic (e.g., size exclusion chromatography) or electrophoretic (e.g., 1- and 2-dimensional gel electrophoresis) separation techniques to the MALDI and ESI instrument. If MS is to fulfil its potential in S-layer research as outlined, it is imperative that easier to use and less expensive MS instrumentation is required and the necessity for the early integration of mass spectrometry in protein and/or glycoconjugate research is recognized. Although remarkable progress has been made during the past few years, much work remains to be done.

\section{Uncited reference}

\section{Acknowledgments}

C.S, T.W. and P.M appreciate the critical discussions with Prof. Uwe B. Sleytr and the excellent technical assistance of Sonja Zayni, Andrea Scheberl, and Manuela Glozik. Their work was supported in part by grants from the Austrian Science Foundation, project S7201-MOB, the Federal Ministry of Sience, Transportation, and the Austrian National Bank, Project 5525.

H.K. acknowledges support by grants of the Hochschulsonderprogramm II of the University of Ulm, the Deutsche Forschungsgemeinschaft, and the Fonds der Chemischen Industrie.

The work by G.A., M.D. and P.M. was supported in part by grants from the Austrian Science Foundation (P 9545CHE and P 11183CHE to G.A.). The authors thank A. Ashcroft and M. Karas for their assistance in obtaining experimental results and E.R. Schmid for his support in the starting phase.

\section{References}

[1] Lechner, J., Wieland, F. (1989) Structure and biosynthesis of prokaryotic glycoproteins. Annu. Rev. Biochem. 58, 173194.

[2] Sumper, M., Wieland, F.T. (1995) Bacterial glycoproteins. In: Glycoproteins (Montreuil, J., Viegenthart, J.F.G., Schachter, H., Eds.), pp. 455-473. Elsevier, Amsterdam.

[3] Messner, P. (1996) Chemical composition and biosynthesis of S-layers. In: Crystalline Bacterial Cell Surface Proteins (Sleytr, U.B., Messner, P., Pum, D., Sára, M., Eds.), pp. 35-76. R.G. Landes/Academic Press, Austin, TX.

[4] Messner, P., Sleytr, U.B. (1991) Bacterial surface layer glycoproteins. Glycobiology 1, 545-551.

[5] Messner, P. Bacterial glycoproteins. Glycoconjugate J., 14, 311.

[6] Kärcher, U., Schröder, H., Haslinger, E., Allmaier, G., Schreiner, R., Wieland, F., Haselbeck, A., König, H. (1993) Primary structure of the heterosaccharide of the surface glycoprotein of Methanothermus fervidus. J. Biol. Chem. 268, 26821-26826.

[7] Wieland, F., Heitzer, R., Schaefer, W. (1983) Asparaginylglucose: novel type of carbohydrate linkage. Proc. Natl. Acad. Sci. USA 80, 5470-5474.

[8] Pellerin, P., Fournet, B., Debeire, P. (1990) Evidence for the glycoprotein nature of the cell sheath of Methanosaeta-like cells in the culture of Methanothrix soehngenii strain FE. Can. J. Microbiol. 36, 631-636.

[9] Mengele, R., Sumper, M. (1992) Drastic differences in glycosylation of related S-layer glycoproteins from moderate and extreme halophiles. J. Biol. Chem. 267, 8182-8185.

[10] Möschl, A., Schäffer, C., Sleytr, U.B., Messner, P., Christian, R., Schulz, G. (1993) Characterization of the S-proteins of two lactobacilli. In: Advances in Bacterial Paracrystalline Surface Layers (Beveridge, T.J., Koval, S.F., Eds.), pp. 281-284. Plenum Press, New York.

[11] Messner, P., Christian, R., Kolbe, J., Schulz, G., Sleytr, U.B. (1992) Analysis of a novel linkage unit of O-linked carbohydrates from the crystalline surface layer glycoprotein of Clostridium thermohydrosulfuricum S102-70. J. Bacteriol. 174, 2236-2240.

[12] Messner, P., Sleytr, U.B. (1988) Asparaginyl-rhamnose: A novel type of protein-carbohydrate linkage in a bacterial surface-layer glycoprotein. FEBS Lett. 228, 317-320.

[13] Messner, P., Christian, R., Neuninger, C., Schulz, G. (1995) Similarity of "core" structures in two different glycans of tyrosine-linked bacterial S-layer glycoproteins. J. Bacteriol. 177, 2188-2193.

[14] Bock, K., Schuster-Kolbe, J., Altman, E., Allmaier, G., Stahl, B., Christian, R., Sleytr, U.B., Messner, P. (1994) Primary structure of the $O$-glycosidically linked glycan chain of the crystalline surface layer glycoprotein of Thermoanaerobacter thermohydrosulfuricus L111-69. Galactosyl tyrosine as a novel linkage unit. J. Biol. Chem. 269, 7137-7144.

[15] Messner, P., Schuster-Kolbe, J., Schäffer, C., Sleytr, U.B., Christian, R. (1993) Glycoprotein nature of select bacterial S-layers. In: Advances in Bacterial Paracrystalline Surface 
Layers (Beveridge, T.J., Koval, S.F., Eds.), pp. 95-107. Plenum Press, New York.

[16] Collins, M.D., Lawson, P.A., Willems, A., Cordoba, J.J., Fernandez-Garayzabal, J., Garcia, P., Cai, J., Hippe, H., Farrow, J.A.E. (1994) The phylogeny of the genus Clostridium: Proposal of five new genera and eleven new species combinations. Int. J. Syst. Bacteriol. 44, 812-826.

[17] Peters, J., Rudolf, S., Oschkinat, H., Mengele, R., Sumper, M., Kellermann, J., Lottspeich, F., Baumeister, W. (1992) Evidence for tyrosine-linked glycosaminoglycan in a bacterial surface protein. Biol. Chem. Hoppe-Seyler 373, 171-176.

[18] Altman, E., Schäffer, C., Brisson, J.-R., Messner, P. (1995) Characterization of the glycan structure of a major glycopeptide from the surface layer glycoprotein of Clostridium thermosaccharolyticum E207-71. Eur. J. Biochem. 229, 308315.

[19] Altman, E., Schäffer, C., Brisson, J.-R., Messner, P. (1996) Isolation and characterization of an amino sugar-rich glycopeptide from the surface layer glycoprotein of Thermoanaerobacterium thermosaccharolyticum E207-71. Carbohydr. Res 295, 245-253.

[20] Altman, E., Brisson, J.-R., Messner, P., Sleytr, U.B. (1990) Chemical characterization of the regularly arranged surface layer glycoprotein of Clostridium thermosaccharolyticum D120-70. Eur. J. Biochem. 188, 73-82.

[21] Schäffer, C., Wugeditsch, T., Neuninger, C., Messner, P. (1996) Are S-layer glycoproteins and lipopolysaccharides related? Microbial Drug Resistance 2, 17-23.

[22] Meier-Stauffer, K., Busse, H-J., Rainey, F.A., Burghardt, J., Scheberl, A., Hollaus, F., Kuen, B., Makristathis, A., Sleytr, U.B., Messner, P. (1996) Description of Bacillus thermoaerophilus sp.nov., to include sugar beet isolates and Bacillus brevis ATCC 12990. Int. J. Syst. Bacteriol. 46, 532-541.

[23] Kosma, P., Wugeditsch, T., Christian, R., Zayni, S., Messner, P. (1995). Glycan structure of a heptose-containing glycoprotein of Bacillus thermoaerophilus. Glycobiology 8, 791-796.

[24] Holst, O., Brade, H. (1992) Chemical structure of the core region of lipopolysaccharides. In: Bacterial Endotoxic Lipopolysaccharides (Morrison, D.C., Ryan, J.L., Eds.), Vol. 1, pp. 135-170. CRC Press, Boca Raton, FL.

[25] Kondo, S., Watabe, T., Haishima, Y., Hisatsune, K. (1993) Identification of oligosaccharides consisting of D-glucuronic acid and L-glycero-D-manno- and D-glycero-D-manno-heptose isolated from Vibrio parahaemolyticus $\mathrm{O} 2$ lipopolysaccharide. Carbohydr. Res. 245, 353-359.

[26] Sidroczyk, Z., Swierzko, A., Lipinska, M., Vinogradov, E.V., Shashkov, A.S., Knirel, Y.A. (1993) Immunochemical studies of O-specific polysaccharide from Proteus penneri 14 lipopolysaccharide. Med. Dosw. Mikrobiol. 45, 85-87.

[27] Khomemko, V.A., Naberezhnych, G.A., Isakov, V.V., Solovèva, T.F., Ovodov, Y.S., Knirel, Y.A., Vinigradov, E.V. (1986) Structural study of O-specific polysaccharide chain of Pseudomonas fluorescens lipopolysaccharide. Bioorg. Khim. 12, 1641-1648.

[28] Lipkind, G.M., Shashkov, A.S., Nifantev, N.E., Kochetkov, N.K. (1992) Computer-assisted analysis of the structure of regular branched polysaccharide containing 2,3-disubstituted rhamnopyranose and mannopyranose residues on the basis of ${ }^{13}$ C NMR data. Carbohydr. Res. 237, 11-22.

[29] Kosma, P., Neuninger, C., Christian, R., Schulz, G., Messner, P. (1995) Glycan structure of the S-layer glycoprotein of $\mathrm{Ba}$ cillus sp. L420-70. Glycoconjugate J. 12, 99-107.

[30] Sutherland, I.W. (1977) Bacterial exopolysaccharides - their nature and production. In: Surface Carbohydrates of the Prokaryotic Cell (Sutherland, I.W., Ed.), pp. 17-69. Academic Press, London.

[31] Osborn, M.J. (1979) Biosynthesis and assembly of the lipopolysaccharide of the outer membrane. In: Bacterial Outer Membranes (Inouye, M., Ed.), p. 15-43. John Wiley and Sons, New York.

[32] Raetz, C.R.H. (1990) Biochemistry of endotoxins. Annu. Rev. Biochem. 59, 129-170.

[33] Whitfield, C. (1995) Biosynthesis of lipopolysaccharide O antigen. Trends Microbiol. 3, 178-185.

[34] Knirel, Y.A., Kochetkov, N.K. (1994) The structure of lipopolysaccharides from Gram-negative bacteria. III. The structure of O-antigens. Biochemistry (Moscow) 59, 1325-1383.

[35] König, H., Kandler, O., Hammes, W. (1989) Biosynthesis of pseudomurein: isolation of putative precursors from Methanobacterium thermoautotrophicum. Can. J. Microbiol. 35, 176181.

[36] Hartmann, E., König, H. (1989) Uridine and dolichyl diphosphate activated oligosaccharides are intermediates in the biosynthesis of the S-layer glycoprotein of Methanothermus fervidus. Arch. Microbiol. 151, 274-281.

[37] Hartmann, E., Messner, P., Allmaier, G., König, H. (1993) Proposed pathway for biosynthesis of the S-layer glycoprotein of Bacillus alvei. J. Bacteriol. 175, 4515-4519.

[38] Shibaev, V.N. (1986) Biosynthesis of bacterial polysaccharide chains composed of repeating units. Adv. Carbohydr. Chem. Biochem. 44, 277-339.

[39] Lechner, J., Wieland, F., Sumper, M. (1985) Transient methylation of dolichyl oligosaccharides is an obligatory step in halobacterial sulfated glycoprotein biosynthesis. J. Biol. Chem. 260, 8984-8989.

[40] Auclair, J. and Accolas, J.P. (1983) Use of thermophilic lactic starters in the dairy industry. Antonie von Leeuwenhoek. 49, 313-326.

[41] Dellaglio, F., Torriani, S., Stefanova-Kondratenko, M., Vlaikovska, K., Ivanova, P. and Mustafova, K. (1986) Presence of Lactobacillus helveticus and an $\mathrm{L}(+)$ lactic acid former in Bulgarian sour milk. Syst. Appl. Microbiol. 8, 223-225.

[42] Yamamoto, N., Akino, A. and Takano, T. (1994) Antihypertensive effect of different kinds of fermented milk in spontaneously hypertensive rats. Biosci. Biotech. Biochem. 58, 776778 .

[43] de Raucourt, A., Girard, D., Prigent, Y. and Boyaval P. (1989) Lactose continuous fermentation with cells recycled by ultrafiltration and lactate separation by electrodialysis: modelling and simulation. Appl. Microbiol. Biotechnol. 30, 521-527.

[44] Torriani, S., Vescovo, M. and Scolari, G. (1994) An overview on Lactobacillus helveticus. Ann. Microbiol. Enzymol. 44, 163-191. 
[45] Ikawa, M. and Snell, E.E. (1960) Cell wall composition of lactic acid bacteria. J. Biol. Chem. 235, 1376-1382.

[46] Masuda, K. and Kawata, T. (1983) Distribution and chemical characterization of regular arrays in the cell walls of strains of the genus Lactobacillus. FEMS Microbiol. Lett. 20, 145-150.

[47] Lortal, S. (1993) Crystalline surface-layers of the genus Lactobacillus. In: Advances in Paracrystalline Surface-Layers (Beveridge, T.J. and Koval, S.F., Eds.), pp. 57-65. Plenum Press, New York.

[48] Lortal, S., van Heijenoort, J., Gruber, K. and Sleytr, U.B. (1992) S-layer of Lactobacillus helveticus ATCC 12046: isolation, characterization and re-formation after extraction with lithium chloride. J. Gen. Microbiol. 138, 611-618.

[49] Lortal, S., Rouault, A., Guezenec, S. and Gautier, M. (1997) Lactobacillus helveticus: strain typing and genome size estimation by pulsed field gel electrophoresis. Curr. Microbiol. 34, 180-185.

[50] Lortal, S. and Mollé, D. (1996) Paracrystalline surface-layers of Lactobacillus helveticus strains. 5th Symp. on Lactic Acid Bacteria, Veldhoven, The Netherlands. Poster D7.

[51] Callegari, M.L., Cocconcelli, P.S., Kok, J., Venema, G., Morelli, L. (1996) Heterologous expression of Lb. helveticus CNRZ 892 S-layer gene in Lc. lactis MG 1363. 5th Symp. on Lactic Acid Bacteria, Veldhoven, The Netherlands. Poster D12.

[52] Boot, H., Kolen, C.P.A.M., Pot, B., Kersters, K., and Pouwels, P.H. (1996) The presence of two S-layer protein encoding genes is conserved among species related to Lactobacillus acidophilus. Microbiology 142, 2375-2384.

[53] Mozes, N. and Lortal, S. (1995) X-ray photoelectron spectroscopy and biochemical analysis of the surface of Lactobacillus helveticus ATCC 12046. Microbiology 141, 11-19.

[54] Lortal, S., Rousseau, M., Boyaval, P. and van Heijenoort, J. (1991) Cell wall and autolytic system of Lactobacillus helveticus ATCC 12046. J. Gen. Microbiol. 137, 549-559.

[55] Rouxhet, P.G., Mozes, N., Dengis, P.B., Dufrêne, Y.F., Gerin, P.A. and Genet, M.J. (1994) Application of X-ray photoelectron spectroscopy to microorganisms. Colloids Surfaces B: Biointerfaces 2, 347-369.

[56] Toba, T., Varkola, R., Westerlund, B., Bjorkman, Y., Silampää, J., Vartio, T., Kalkkinen, N. and Korhonen, T.K. (1995) A collagen-binding S-layer protein in Lactobacillus crispatus. Appl. Environ. Microbiol. 61, 2467-2471.

[57] Greene, J.D. and Klaenhammer, T.R. (1994) Factors involved in adherence of lactobacilli to human Caco-2 cells. Appl. Environ. Microbiol. 60, 4487-4494.

[58] Thorne, C.B. (1993) Bacillus anthracis. In: Bacillus subtilis and other Gram-positive Bacteria. (Sonenshein, A.L., Hoch, J.A. and Losick, R., Eds.), pp. 113-124. American Society for Microbiology, Washington DC.

[59] Bovarnik, M. (1942) The formation of extracellular D(-)glutamic acid poly-peptide by Bacillus subtilis. J. Biol. Chem. $145,415-424$.

[60] Gardner, J.M. and Troy, F.A. (1979) Chemistry and biosynthesis of the poly- $\gamma$-D-glutamyl capsule in Bacillus licheniformis J. Biol. Chem. 254, 6262-6269.

[61] Bruckner, V., Kovacs, J. and Denes, G. (1953) Structure of poly-D-glutamic acid isolated from capsulated strains of B. anthracis. Nature 172, 508.

[62] Torii, M., Kurimura, O., Utsumi, S., Nozu, H. and Amano, T. (1959) Decapsulation of Bacillus megaterium. Biken J. 2, 265-276.

[63] Wietzerbin-Falszpan, J., Das, B.L., Gros, C., Petit, J.-F. and Lederer, E. (1973) The amino acids of the cell wall of Mycobacterium tuberculosis var. bovis strain BCG. Presence of a poly(L-glutamic acid). Eur. J. Biochem. 32, 525-532.

[64] Kandler, O., König, H., Wiegel, J. and Claus, D. (1983) Occurrence of poly- $\gamma$-D-glutamic acid and poly- $\alpha$-glutamine in the genera Xanthobacter, Flexithrix, Sporosarcina and Planococcus. System. Appl. Microbiol. 4, 34-41.

[65] Housewright R.D. (1962) The biosynthesis of homopolymeric peptides. In: The Bacteria. (Gunsalus, I.C. and Stanier, R.Y., Eds.), Vol. 3, pp. 389-412. Academic Press, New York.

[66] Birrer, G.A., Cromwick, A.-M. and Gross, R.A. (1994) $\gamma$-Poly(glutamic acid) formation by Bacillus licheniformis 9945a: physiological and biochemical studies. Int. J. Biol. Macromol. 16, 265-275.

[67] Gardner, J.M. and Troy, F.A. (1979) Chemistry and biosynthesis of the poly( $\gamma$-D-glutamyl) capsule in Bacillus licheniformis. Activation, racemization, and polymerization of glutamic acid by a membraneous polyglutamyl synthetase complex. J. Biol. Chem. 254, 6262-6269.

[68] Meynell, E. and Meynell, G.G. (1964) The role of serum and carbon dioxide in capsule formation by Bacillus anthracis. $\mathbf{J}$. Gen. Microbiol. 34, 153-164.

[69] Thorne, C.B. (1956) Capsule formation and glutamyl polypeptide synthesis by Bacillus anthracis and Bacillus subtilis. In: Bacterial Anatomy (Spooner, E.T.C. and Stocker, B.A.D., Eds.), pp. 68-80. Cambridge University Press, Cambridge.

[70] Troy, F.A. (1973) Chemistry and biosynthesis of the poly $(\gamma$-D-glutamyl) capsule in Bacillus licheniformis. I. Properties of the membrane-mediated biosynthesis reaction. J. Biol. Chem. 248, 305-315.

[71] Troy, F.A. (1973) Chemistry and biosynthesis of the the pol$\mathrm{y}(\gamma$-D-glutamyl) capsule in Bacillus licheniformis. II. Characterization and structural properties of the enzymatically synthesized polymer. J. Biol. Chem. 248, 316-324.

[72] Green, B.D., Battisti, L., Koehler, T.M., Thorne, C.B. and Ivins, B.E. (1985) Demonstration of a capsule plasmid in $\mathrm{Ba}$ cillus anthracis. Infect. Immun. 49, 291-297.

[73] Uchida, I., Sekizaki, T., Hashimoto, K. and Terakado, N. (1985) Association of the encapsulation of Bacillus anthracis with a 60-megadalton plasmid. J. Gen. Microbiol. 131, 363367.

[74] Makino, S.-I., Uchida, I., Terakoda, N., Sasakawa, C. and Yoshikawa, M. (1989) Molecular characterization and protein analysis of the cap region, which is essential for encapsulation in Bacillus anthracis. J. Bacteriol. 171, 722-730.

[75] Thorne, C.B. (1960) Biochemical properties of virulent and avirulent strains of Bacillus anthracis. Ann. N.Y. Acad. Sci. $88,1024-1033$.

[76] Sterne, M. (1939) The use of anthrax vaccines prepared from avirulent (uncapsulated) variants of Bacillus anthracis. Onderstepoort J. Vet. Sci. Anim. Ind. 13, 307-312. 
[77] Goodman, J.W. and Nitechi, D.E. (1966) Immunological studies on the polyglutamyl capsule of Bacillus anthracis. I. Characterization of the polypeptide and of the specifity of its reaction with rabbit antisera. Biochem. 5, 657-665.

[78] Tindall, B.J. (1992) The family halobacteriaceae. In: The Prokaryotes (Balows, A., Trüper, H.G., Dworkin, M., Harder, W. and Schleifer, K.-H., Eds.), Vol. I, pp. 768-808. Springer Verlag, Heidelberg.

[79] Schleifer, K-H., Steber, J. and Mayer, H. (1982) Chemical composition and structure of the cell wall of Halococcus morrhuae. Zbl. Bakt. Hyg., I. Abt. Orig. C3: 171-178.

[80] Kandler, O. and König, H. (1993) Cell envelopes of archaea: structure and chemistry. In: The Biochemistry of Archaea (Archaebacteria) (Kates, M., Kushner, D.J. and Matheson, A.T., Eds.), pp. 223-259. Elsevier Science Publishers, Amsterdam.

[81] Biemann, K., Gapp, F. and Seibl, J. (1959) Application of mass spectrometry to structure problems. I. Amino acid sequence in peptides. J. Am. Chem. Soc. 81, 2274-2275.

[82] Torgerson, D.F., Skowronski, R.P. and Macfarlane, R.D. (1974) New approach to the mass spectroscopy of non-volatile compounds. Biochem. Biophys. Res. Commun. 60, 616-621.

[83] Hakansson, P., Kamensky, I., Sundqvist, B., Fohlman, J., Peterson, P., McNeal, C.J. and Macfarlane, R.D. (1982) Iodine-127 plasma desorption mass spectrometry of insulin. J. Am. Chem. Soc. 104, 2948-2949.

[84] Karas, M. and Hillenkamp, F. (1988) Laser desorption ionisation of proteins with molecular masses exceeding 10000 daltons. Anal. Chem. 60, 2299-2301.
[85] Tanaka, K., Waki, H., Ido, Y., Akita, S., Yoshida, Y. and Yohida, T. (1988) Protein and polymer analyses up to $\mathrm{m} / \mathrm{z}$ 100000 by laser ionisation time-of-flight mass spectrometry. Rapid Commun. Mass Spectrom. 2, 151-153.

[86] Meng, C.K., Mann, M. and Fenn, J.B. (1988) Of protons or proteins. Z. Phys. D 10, 361-368.

[87] Allmaier, G. (1995) Mass spectrometry - Applications in peptide and protein chemistry. In: Encyclopedia of Analytical Science (Townshend, A., Ed.), pp. 3003-3011. Academic Press, London.

[88] Allmaier, G., Schäffer, C., Messner, P., Rapp, U. and MayerPosner, F.-J. (1995) Accurate molecular weight determination of the major surface layer protein isolated from Clostridium thermosaccharolyticum by time-of-flight mass spectrometry. J. Bacteriol. 177, 1402-1404.

[89] Lortal, S., Rouault, A., Cesselin, B. and Sleytr, U.B. (1993) Paracrystalline surface layers of dairy propionibacteria. Appl. Environ. Microbiol. 59, 2369-2374.

[90] Christian, R., Schulz, G., Schuster-Kolbe, J., Allmaier, G., Schmid, E.R., Sleytr, U.B. and Messner, P. (1993) Complete structure of the tyrosine-linked saccharide moiety from the surface layer glycoprotein of Clostridium thermohydrosulfuricum S-102-70. J. Bacteriol. 175, 1250-1256.

[91] Dorner, M. (1996) Matrixunterstützte Laserdesorption/ Ionisationsmassenspektrometrie von Zuckernukleotiden. M.Sc. thesis, University of Vienna.

[92] Domon, B. and Costello, C.E. (1988) A systematic nomenclature for carbohydrate fragmentations in FAB-MS/MS spectra of glycoconjugates. Glycoconjugate J. 5, 397-409. 